\title{
Tax Enforcement, Tax Compliance and Tax Morale in Transition Economies: A Theoretical Model
}

\author{
by \\ RANDOLPH LUCA BRUNO*
}

The focus of this paper is the analysis of the relationship between tax enforcement, tax compliance and tax morale within countries characterised by rapid introduction of market institutions and slow evolution of political regimes, such as transition economies. The paper investigates a coordination game in which the government is ex-ante committed to tax enforcement and can observe the proportion of taxcompliant agents in the economy. In turn, two groups of agents (third-party reporting and self-reported income) are keen to evade taxes unlawfully but have limited information on how many others evade taxes; their tax morale is therefore an endogenous function of agents' perception on tax compliance. The model predicts that the lower the quality of political institutions and the weaker tax morale, the less tax compliance can be achieved. The third-party reporting group will also be bearing higher tax burden than the self-reported income group. The model entails that having political institutions of good quality is not a sufficient condition to conduce to tax enforcement or tax compliance. Due to the endogenous role of tax morale, the government could be pushed ex-post towards poor or no tax enforcement. If good political institutions are not accompanied by good information about the enforcement of tax collection, there is scope for co-existence of poor tax enforcement, low tax compliance and weak tax morale. As such, this model well describes the tax evasion behaviour observed since the outset of transition from planned to market economy. (JEL: D81, K42, P26)

${ }^{*}$ Randolph Luca Bruno, University College London, School of Slavonic and East European Studies, 16, Taviton Street, London, WC1H OBW, E-mail: randolph.bruno@ucl.ac.uk 


\section{Introduction}

The transition process from centrally planned economies to democratic societies entails fundamentally reshaping legal institutions within countries. Abrupt political changes might well result in a window of opportunity to implement pro-market reforms, such as the enforcement of property rights within the rule of law, broad access to those rights and predictable rules uniformly enforced by courts and regulators, all elements of a democratic society. However, the transition process has witnessed a variety of illegal activities, such as tax evasion, asset-stripping, self-dealing, consumption of perks, outright expropriation of shareholders, tunnelling, creative accounting, opportunistic managerial behaviour, and lobbying to limit active monitoring, to name a few. Some politicians and managers maintained control over physical capital from the planned economy but did not pay full market prices for those privatised assets (Campos and Giovannoni [2006]). This phenomenon was a clear infringement of the rule of law. Indeed, the 'rule of law' in this respect has hardly emerged in some economies such as Russia or Ukraine, where high levels of corruption - a reflection of the absence of the rule of law are still an unpleasant reality (Levin and Satarov [2000]).

Schneider and Enste 2000]1 Schneider [2005], Schneider [2017] and Frey and Torgler [2007] document how the evolution of the shadow economy around the world as well in transition economies from the 1990s - the first decade of the transformation process towards a market economy - was paralleled by an increase in tax evasion, resembling a pattern closer to underdeveloped African and South American countries rather than highly developed OECD economies. As shown in Table 1, from 1991 to 2015 the estimated shadow economy in transition countries amounted to $35 \%$ of GDP on average, compared to $9 \%$ in the United States. This average masks substantial cross-country variation, ranging from $16 \%$ in the Slovak Republic, now an EU country, to $65 \%$ in Georgia, a former Soviet Union (FSU) country; yet it is still a clear indication of the overall magnitude of the phenomenon. Considering the states that are EU members as a cluster, they score much better than the FSU countries overall, not only on the shadow economy indicator, but also on three important institutional context variables such as the Corruption Perception Index, the Polity 2 index, and rents from natural resources.

Slemrod 2007] has looked into the details of the economics of tax evasions in major advanced economies like the United States. In line with the literature, the author concludes that deterrence and the rule of law - key elements of a full-fledged tax enforcement strategy - enhance tax compliance, which is defined as the lack of both tax evasion and tax avoidance. This paper links the two concepts - tax enforcement and tax (non-)compliance - to a third notable phenomenon which has recently received a lot of attention in the public economics literature: tax morale. Tax morale can be defined as voluntary compliance with tax law and creating a social norm of compliance, as in Luttmer and Singhal [2014], a notable literature review on the mechanisms through

1 Schneider and Enste 2000 report a detailed taxonomy of underground economic activities (Table 1): monetary vs. non-monetary transactions, illegal vs. legal activities and tax avoidance vs. tax evasion. Tax evasion is further broken down into 'unreported income from self-employment, wages and salaries and assets from unreported work. 


\begin{tabular}{|c|c|c|c|c|c|c|c|}
\hline \multirow[b]{2}{*}{ Country } & \multicolumn{4}{|c|}{ Shadow Economy(a), as \% of GDP } & \multicolumn{3}{|c|}{ Institutional Context(b) } \\
\hline & 1991-2003 & 2004-2015 & $1991-2015$ & Group & $\begin{array}{c}\mathrm{CPI} \\
\mathrm{TI}\end{array}$ & $\begin{array}{c}\text { Polity } \\
\text { Dem.-Aut. }\end{array}$ & $\begin{array}{l}\text { Nat. Res. } \\
\text { (\% of GDP) }\end{array}$ \\
\hline Albania & 37.58 & 27.45 & 32.72 & n.a. & 36 & 9 & 1.8 \\
\hline Armenia & 46.43 & 38.44 & 42.59 & FSU & 35 & 5 & 4.6 \\
\hline Azerbaijan & 58.55 & 45.30 & 52.19 & FSU & 29 & -7 & 13.3 \\
\hline Belarus & 50.03 & 38.56 & 44.52 & FSU & 32 & -7 & 1 \\
\hline Bosnia \& Herzegovina & 35.96 & 32.32 & 34.21 & SFRY & 38 & - & 1 \\
\hline Bulgaria & 35.44 & 25.71 & 30.77 & $\mathrm{EU}$ & 41 & 9 & 1.5 \\
\hline Croatia & 34.32 & 25.85 & 30.25 & $\mathrm{EU}$ & 51 & 9 & 0.7 \\
\hline Czech Republic & 19.38 & 14.70 & 17.13 & $\mathrm{EU}$ & 56 & 9 & 0.1 \\
\hline Estonia & 32.28 & 25.02 & 28.8 & $\mathrm{EU}$ & 70 & 9 & 1 \\
\hline Georgia & 67.39 & 62.15 & 64.87 & FSU & 52 & 7 & 1 \\
\hline Hungary & 28.41 & 21.71 & 25.19 & $\mathrm{EU}$ & 51 & 10 & 0.3 \\
\hline Kazakhstan & 43.86 & 33.47 & 38.88 & FSU & 28 & -6 & 10.3 \\
\hline Kyrgyzstan & 41.44 & 34.10 & 37.92 & FSU & 28 & -7 & 7.2 \\
\hline Latvia & 29.45 & 22.32 & 26.03 & $\mathrm{EU}$ & 56 & 8 & 0.9 \\
\hline Lithuania & 31.34 & 23.85 & 27.75 & $\mathrm{EU}$ & 59 & 10 & 0.4 \\
\hline Moldova & 45.26 & 41.46 & 43.43 & FSU & 33 & 9 & 0.4 \\
\hline Poland & 30.06 & 22.65 & 26.5 & $\mathrm{EU}$ & 63 & 10 & 0.8 \\
\hline Romania & 33.54 & 26.42 & 30.13 & $\mathrm{EU}$ & 46 & 9 & 1 \\
\hline Russian Federation & 46.68 & 38.12 & 42.57 & FSU & 29 & 4 & 10 \\
\hline Slovak Republic & 19.11 & 13.94 & 16.63 & $\mathrm{EU}$ & 51 & 10 & 0.3 \\
\hline Slovenia & 28.47 & 23.32 & 25.99 & $\mathrm{EU}$ & 60 & 10 & 0.2 \\
\hline Tajikistan & 44.67 & 41.17 & 42.99 & FSU & 26 & -3 & 2.1 \\
\hline Ukraine & 48.65 & 40.64 & 44.8 & FSU & 27 & 4 & 4 \\
\hline Transition countries & 38.62 & 31.24 & 35.08 & - & 43.35 & 5.05 & 2.78 \\
\hline United States & 9.83 & 8.98 & 9.42 & G7 & 76 & 10 & 0.3 \\
\hline
\end{tabular}

Table 1 Transition Countries: The Role of the Shadow Economy and the Institutional

\section{Context}

Sources: a) The data on the shadow economy are from Schneider 2005, Schneider 2017] and Schneider and Enste 2000] using the wellestablished 'Multiple Indicators, Multiple Causes (MIMIC) approach'; EU = European Union; FSU = Former Soviet Union; SFRY = Socialist Federal Republic of Yugoslavia; some countries were part of the FSU or SFRY, however for classification purposes the latter affiliation to the EU has been reported; Albania, a transition country, does not belong to any grouping; the USA is added as an advanced economy comparator. b) CPI: Corruption Perception Index, Transparency International (2015) the higher the figure, the lower the corruption; Polity 2 index of democratisation and autocracy (2015), the higher the figure, the more democratic a country is (data not available for Bosnia \& Herzegovina); total natural resources rents (\% of GDP in 2015) - World Bank: Total natural resources rents are the sum of oil rents, natural gas rents, coal rents (hard and soft), mineral rents, and forest rents as \% of GDP. Bold text denotes the maximum value and italics denotes the minimum value in each column. 
which tax morale operates in the context of difficult tax enforcement and compliance.

At the start of the transition process, some scholars (e.g. Boycko, Shleifer and Vishny [1995]) argued that applying the rule of law was a second order phenomenon, meaning that as soon as property rights became sufficiently widespread (despite the fact that they were not yet protected), citizens and economic agents like firms and corporations would form political constituencies acting as social pressure groups. In turn, lobbies would compel politicians to adopt policies with the aim of protecting precisely those property rights, such as tax compliance. These authors' stance has been challenged by Hoff and Stiglitz 2004a and Hoff and Stiglitz 2008, who argue that the probability distribution of the political outcome depends on the fraction of the population that chooses to build value, which itself depends on the probability of the political outcome. This concept of 'conditional cooperation' (see Traxler [2010] and Frey and Torgler 2007]) fits the context of transition economies. In other words the relationship between tax enforcement, tax evasion and tax morale is conditional upon a particular historical context, i.e. the transition from planned to market economy, where political institutions tend to change very slowly.

In light of these ideas, this paper develops a theoretical model of tax enforcement, tax compliance and tax morale where a key role is played by the institutional context. A fully-functioning institutional context could favour tax enforcement via deterrence and the rule of law. However, the emergence of tax enforcement and tax compliance will be jointly and endogenously determined by tax morale through the role of imperfections in information, that is, through deviations from the traditional expected utility theory on tax evasion, as in Allingham and Sandmo 1972, where it is assumed that all economic agents are fully informed.

For this purpose, we model the behaviour of agents who strategically evaluate whether to pay taxes or avoid doing so (e.g. by stripping assets, tunnelling and/or underreporting income). Imperfect information on institutional quality (e.g. of the court system and, broadly speaking, of political institutions) entails a misperception of other players' actions. The model predicts that whenever there is high uncertainty over the proportion of agents evading taxes (as occurs, for instance, in institutionally weak societies) and the sunk costs the government must sustain for tax enforcement are high, we observe a convergence towards low tax morale and low tax compliance. If institutions are sound and tax evasion is costly (as would be the case given an efficient judiciary), then tax morale rises spontaneously.

This paper is organised as follows: section 2 reviews the pertinent literature; section 3 presents the building blocks of the model; the model is solved for the equilibrium under perfect information in section 4 , the benchmark case, and then for imperfect information in section 5, the fully-fledged model. Concluding points are then expressed in section 6 .

\section{Literature Review}

The seminal paper on tax evasion by Allingham and Sandmo [1972 shows how the expected utility approach (taxpayers as gamblers) can be applied to the 'economics of tax evasion' in the broader sphere of the economics of crime. Subsequently, many scholars 
have followed their approach by expanding and extending this model in different contexts within the growing evidence-driven research area of tax evasion. For example, Naylor [1990] and Myles and Naylor [1996] and Myles [2000 have theoretically analysed how social customs shape the way a group of people implement collective actions, including paying taxes, which is a fundamental building block of society, given its ultimate aim of providing good quality public goods and economic development. Orviska and Hudson 2002 also show some data on tax evasion attitudes from a sample survey conducted in the UK and identify both civic duty and law abidance as key elements in deterring tax evasion.

The literature has been investigating whether the relationship between tax enforcement and tax compliance is always positive. Bork 2004] challenges the conventional view that tax enforcement is always found together with tax compliance, by showing that tax enforcement could, when combined with high tax rates and high retributive transfer, have the perverse effect of greater tax evasion. This is a counter-intuitive result which would not be predicted in the standard Allingham and Sandmo [1972] model. Torgler 2005] and Frey and Torgler 2007] analyse the nexus between institutional quality (e.g. Swiss direct democracy) and tax morale, and show their intertwined relationship. Furthermore, Traxler 2010 is one of the first contributors to model tax morale endogenously within the expected utility approach (building on Naylor [1990] and Myles and Naylor [1996]), by looking at the social norm for tax compliance. This seminal paper develops the theory in two directions: on one hand, it models tax morale as a function of other taxpayers' compliance; on the other hand, it looks specifically at the heterogeneous nature of those taxpayers, which can be clustered within morale reference groups. As an empirical counterpart, Lago-Penas and Lago-Penas [2010] show how tax morale varies according to socio-demographic characteristics when looking at a comprehensive Europe Social Survey conducted by the OECD. Finally, a paper by Filippin, Fiorio and Viviano 2013 links tax enforcement, tax morale and tax compliance in a unified setting and tests the relationship with high-quality data from the Italian Survey of Household Income and Wealth. Their results show how the literature has overlooked the indirect effect of tax enforcement on compliance via tax morale.

Drawing from this literature, the main contribution of the present paper is a theoretical investigation of the endogenous relationship between tax enforcement and tax compliance via tax morale. This paper posits that even if institutional quality (e.g. as in Williamson [2000]) and tax morale (see Luttmer and Singhal [2014]) are different dimensions of society, the latter can well be enhanced and improved by the dissemination of quality information on political institutions in the society as a whole. In fact, transition countries are considered an ideal context for this natural experiment: tax enforcement and tax compliance both tend to be particularly low (vis-à-vis OECD economies) and the relatively low level of tax morale might be a crucial explanatory factor.

Dixit [2004] provides a comprehensive review of the literature on the phenomenon of lawlessness, while Levin and Satarov [2000] gives a compelling account of the monetary impact of lawlessness, including via tax evasion, in Russia. The author points out that even under well-functioning laws, imperfect information, externalities and imperfect competition are well-recognized causes of market failures, and they can exist 
regardless of whether a government adequately protects property rights and enforces contracts. The contribution by Katz 2008 contends that the efficacy of different enforcement mechanisms depends on information and other transaction costs, as well as their complementarity or substitutability with the government tribunal system.

Murphy, Shleifer and Vishny 1993 and Sonin [2003 focus on the rent-seeking behaviour of state-oligarchs in the presence of individual incentives to break the rule of law, i.e. by paying bribes and avoiding taxes. Roland and Verdier [2003, Hoff and Stiglitz 2004a and Hoff and Stiglitz 2008 model strategic complementarities and determine the existence of multiple equilibria where ex-ante weak demand for rule of law is endogenously determined by low expectation of enforcement ex-post. Players' payoffs are affected by strategic complementarities. This paper adopts a framework à la Carlsson and van Damme 1993a/Carlsson and van Damme 1993b, with multiple equilibria in the presence of coordination failure and strategic complementarities. In fact, good market institutions do not constitute a sufficient condition for the establishment of good "rules of the game" in the realm of property rights and tax enforcement. Inadequate institutions entail weak property rights protection, but sound legal institutions might contribute to improved rule of law enforcement only if there is widespread information about the strength of those institutions. In other words, good institutions and good information about institutions are not necessarily found together. Blurred visibility of institutional strength is, per se, an institutional weakness.

\section{The Model}

This paper builds on the theoretical framework developed by Hoff and Stiglitz $|2004 \mathrm{a}|^{2}$ describing the post-privatisation context of transition economies. Due to the transfer of control rights over to private actors, there is an expectation of increased demand for law enforcement, precisely because implementation of the rule of law is tantamount to protection of those right:3. However, potential taxpayers are also opportunistically attracted by the wealth they can obtain from evasion. The strategies adopted by the players are described below.

\footnotetext{
${ }^{2}$ See Hoff and Stiglitz 2008 on the difference between control and property in the context of transition countries.

3 Cooter 1996 highlighted the differences between rule of law state and rule of state law:

"The Soviet Union exemplified the rule of State law, [...]. Since state law did not respond to morality, spontaneous support for law by citizens was weak. Soviet citizens, who were accustomed to a low level of spontaneous support for law by citizens, must have expected this tradition to continue after the Soviet government collapsed. These expectations created a self-fulfilling prophecy and caused the system to conduce to low private support for state law, which in turn made state law ineffective. The situation is the opposite of the rule of the law State [...]".
} 


\subsection{Strategy elements of the tax game}

A continuum of economic agents (also called citizens in the paper) makes decisions about tax compliance. The government, as the ultimate supplier of public goods and services, decides whether to implement tax enforcement or surrender to anarchy.

This continuum of agents is divided in two groups: a group whose income is reported by third parties (e.g. civil servant employees) and a group whose income is only selfreported (e.g. business owners). The former group has limited scope for evading taxes, whereas the latter possesses a much wider array of options and opportunities (see Kleven, Knudsen, Kreiner, Pesersen and Saez [2011]). This division of the society as income earners into two broad sections will have key distributional implications.

We call $\theta$ the institutional quality in an economy, uniformly distributed on the $[0,1]$ interval. High $\theta$ is attached to 'high type' economies, while low $\theta$ characterises 'low type' economies. Neither the two groups of agents' actions nor the government's actions have any effect on this exogenous parameter (as evidenced by the statistics in the last three columns of Table 1). Citizens must gauge the value of $\theta$, while the government has full knowledge, i.e. there is no uncertainty whatsoever on the parameter of the game for the government. The model therefore explains the supply side (tax enforcement) and demand side (tax compliance) once the institutional quality and relevant information are known. Two layers of institutions interplay: a fast-moving one (the tax enforcement) and a slow-moving one (the fundamentals) (Roland [2004, Williamson [2000]). For our short-medium run analysis, we will assume that the former is endogenous and the latter is exogenous.

Agents have expectations about the establishment of tax enforcement. As a general rule, they prefer to evade taxes if they do not expect to receive full protection of their assets in the futur€ $\biguplus^{4}$ as Stiglitz explains: "If you got $\$ 1-\$ 2$ billion in assets through illegal privatization, you would fear the next government in power would take it back so the best thing to do is not to reinvest in the country but to take it out as fast as you can. By moving assets to Western countries, oligarchs enjoyed the best of two worlds: they had property rights protected abroad and weak rule of law at home."

In this model, the government and the two groups of agents are de-facto playing on the (re-)'distribution' of tax revenues. Broadly speaking, these assets can be evaded by both groups of taxpayers, which will lead to poor provision of public goods and services; otherwise, they can be protected by tax enforcement, which will allow the government to redistribute them in the form of public goods and services, enjoyed by everyone. Agents calculate rationally whether to evade taxes once they have formulated their expectations of being detected and punished via tax enforcement, with respect to how much they would lose in the form of public goods and services, in the spirit of the seminal paper on tax evasion Allingham and Sandmo 1972.

\footnotetext{
${ }^{4}$ In line with Hoff and Stiglitz 2004a], the story behind the demand for law enforcement is a simplification of the hypotheses put forward in the vast literature on rule of law and property rights protection.
} 


\subsubsection{Strategies of the players}

- Government The government might enforce tax collection but, unfortunately, this is not always its optimal choice. It decides whether to fully enforce the collecting of taxes $\gamma=\left[\gamma_{1}+\gamma_{2}=\gamma\left(w_{1}+w_{2}\right)\right]$ and to redistribute them in the form of public goods and services, or to abandon the economy to anarchy by getting zero revenue from tax collection.

- Agents Without tax enforcement, both groups of citizens have better control over enterprises, assets and income $\gamma$, via tax evasion. This is a similar strategy model to the inter-group spillover concept analysed by Traxler [2010] in his tax evasion model. Citizens not paying taxes could be caught and punished, and/or experience diminished provision of public goods. Every member of each of the two groups will choose to either pay or evade taxes. These two groups are characterised by different tax evasion propensities (in the spirit of Kleven, Knudsen, Kreiner, Pesersen and Saez 2011]) and by different returns in the form of public goods (see Traxler [2010]). In equilibrium, the third-party reporting group will have lower tax evasion propensity and greater benefits from public goods and services, whereas the self-reported income group will have higher tax evasion propensity and lower benefits from public goods and services. However, the tax evasion behaviour of the third party reporting has a spillover effect on the self-reporting group and vice-versa.

\subsection{Tax Enforcement and Tax Evasion Capacity}

The payoff of the government and citizens is a function of other players' actions. The government gains in two cases: when the economy has high institutional quality (high $\theta$ ), and when the proportion of citizens evading taxes $\alpha \in[0,1]$ is low. In other words, it is easiest to enforce taxes when economic institutions are strong and when few agents evade.

The agents payoff, on the other hand, is positively correlated with the number of other agents evading $(\alpha)$, and inversely correlated with the institutional quality of the economy $(\theta)$. However, 'type 1' (third-party reporting) and 'type 2' (self-reporting) agents will show different equilibrium tax evasion levels where $\left(\alpha_{1}+\alpha_{2}=\alpha\right)$, where the subscript stands for the type of agent. Intuitive reasoning is given below, while a case-by-case taxonomy of the payoffs is provided further ahead, in section 3.2.1 and a fully-fledged step-by-step graphical interpretation is shown in section 3.2.2. Table 3 will summarise.

For the sake of argument, if the level of $\theta$ in the economy is kept constant (something one might do in order to compare different scenarios of tax evasion within a country), then the higher/lower the number of agents evading taxes $\alpha_{i}$, the higher/lower the tax enforcement (evasion) cost: 5 . Now, by the same token, if $\alpha$ remains constant (which

\footnotetext{
${ }^{5}$ The direct spillover effect among agents is not necessary to obtain the coordination failure result in Morris and Shin 1998. On the contrary, in this paper that effect does matter in terms of equilibrium
} 
would enable a comparison countries with similar tax evasion rate), the higher/lower the institutional quality within the economy, the lower/higher the tax enforcement (evasion) costs.

Table 2

Citizen Groups

\begin{tabular}{l|l|l|l|l|l}
\hline Group $i$ & \multirow{5}{*}{ Tax regime } & $\begin{array}{l}\text { Groups' } \\
\text { Weight }\end{array}$ & $\begin{array}{l}\text { Tax } \\
\text { Revenue }\end{array}$ & $\begin{array}{l}\text { Tax evasion } \\
\text { Cost }\end{array}$ & $\begin{array}{l}\text { Tax evasion } \\
\text { Attitude }\end{array}$ \\
& & & & & \\
\hline Type-1 & third-party reporting & $w_{1}$ & $\gamma_{1}=w_{1} \gamma$ & $t_{1}$ & $\alpha_{1}$ \\
Type-2 & self-reported income & $w_{2}$ & $\gamma_{2}=w_{2} \gamma$ & $t_{2}$ & $\alpha_{2}$ \\
\hline
\end{tabular}

\subsubsection{Structure of the tax game: the players options and strategies}

- Government fully enforces tax collection if all tax revenues are worth $\gamma$. Tax revenues are in turn composed of two parts $\left(\gamma_{1}+\gamma_{2}=\gamma\right)$ : revenue from the third-party reporting group $\gamma_{1}=w_{1} \gamma$ and revenue from the self-reporting group $\gamma_{2}=w_{2} \gamma$. Fully enforcing tax collection comes at a cost: $k-\theta$ is the fixed cost ( $k$ and $\theta$ are exogenous parameters in the modelling strategy), where $c(\alpha, \theta)=\alpha$ is the variable cost, the proportion of agents evading taxes. In other words, the sum of the fixed and variable costs is $[k+\alpha]-\theta$, which is an increasing function in $k, \alpha$ and decreasing in $\theta$, the economys institutional quality as per our previous intuition, $\frac{\partial c}{\partial \alpha}>0, \frac{\partial c}{\partial \theta}<0$. If the government enforces taxes, its payoff is overall tax revenues minus the costs, $\gamma-[k+\alpha]-6^{6}$.

- Government does not enforce tax collection and therefore it does not recover any tax revenues nor pay any cost. Its payoff is simply 0 and anarchy prevails?.

- Agents evade (and try to illegally appropriate) taxes and thus pay a fixed cost $t+\theta$ ( $t$ and $\theta$ are exogenous parameters in the modelling strategy) as well as a variable negative $\operatorname{cost} \alpha$. The reason why there is a negative cost, i.e. a benefit, was spelled out at the start of section 3.2 . citizens lose only when few other fellow

outcome. Strategic interactions among players have been modelled in a similar theoretical fashion by Cooter 1996 and Roland and Verdier 2003.

${ }^{6} \mathrm{We}$ assume that $c(\alpha, \theta)=\alpha-\theta$ because this is a simple linear function increasing in the proportion of $\alpha$ and decreasing in the economy's institutional quality level $\theta$. Morris and Shin [1998] assume a generic monotonic and continuous function $c(\alpha, \theta)$ and derive and prove the unique equilibrium result. A linear function is both monotonic and continuous and satisfies the conditions for the existence of a unique equilibrium. The model is therefore a sub-case of their analysis.

${ }^{7}$ It would be possible to consider an out-of-equilibrium outcome in which the state gets $\gamma$ if nobody evades, even if tax enforcement is zero. However, this out-of-equilibrium outcome has zero de-facto probability, i.e. there will always be a noise criminal not paying taxes, so it is an irrelevant case in the analysis of equilibria selection in the multiple agents game. For the single-agent game, see the appendix. 
citizens evade, but gain otherwise. Following this logic, whatever is a cost will enter the overall payoff with a negative sign, they pay $t+\theta$ but gain (negative cost) a positive signed $a^{8}$. (For a similar modelling strategy, see Traxler [2010] and Kandori [1992]). Type 1 citizens will face higher fixed costs $t_{1}>t_{2}$ than type 2 citizens but exactly the same $\theta$. This is due to the intrinsic nature of third-party reporting: the probability of being caught is much higher and they are constrained in their actions (Allingham and Sandmo [1972]). Traxler [2010] justifies a similar choice by referring to citizens of the same local community with similar education, income or social status (in Russia, for example, we still observe a stark difference between oligarchs and ordinary citizen $\mathbf{9}^{9}$ ). Citizens, whose population size of the two groups together is normalised to 1, face two cases when they evade:

- Case 1. They evade and the government enforces. They lose all tax revenues $\gamma=\gamma_{1}+\gamma_{2}$, and the payoff of the evading citizen is therefore $0-\left[t_{i}+\theta\right]+\alpha$, $i=1,2^{10}$

- Case 2 They evade and the government does not enforce. The value of typespecific tax evasion is $w_{i} \gamma=\gamma_{i}$, by generating a payoff of $\gamma_{i}-\left[t_{i}+\theta\right]+$ $a^{11}$. However, the two groups of citizens would benefit differently from their strategies, as $\gamma_{1} \neq \gamma_{2}$.

- When agents pay taxes, they see no personal gain but do not incur any cost of evasion, i.e. the payoff is $\mathrm{d}^{12}$

Table 3

Basic Payoff Matrix

\begin{tabular}{|r||r|r|}
\hline Agent $(s) \backslash$ Government & Enforce Taxes & not Enforce \\
\hline \hline Pay Taxes & $0 ; \gamma-[k+\alpha]+\theta]$ & $0 ; 0$ \\
\hline Evade Taxes & $-\left[t_{i}+\theta\right]+\alpha ; \gamma-[k+\alpha]+\theta$ & $\gamma_{i}-\left[t_{i}+\theta\right]+\alpha ; 0$ \\
\hline
\end{tabular}

\footnotetext{
${ }^{8}$ The hypothesis that the agents' variable costs are equal in value and opposite in sign with respect to the government's variable costs is a simplification taken for convenience. Any other cost functions, increasing in $\alpha$ and decreasing in $\theta$ for the government and vice-versa for the agents would lead to the same conclusions. For an interpretation see the Appendix. Section 3.2 .2 will analyse this distinction in detail.

${ }^{9} \mathrm{I}$ would like to thank an anonymous referee for this key point.

${ }^{10}$ Both type one and type two citizens are not only affected by the tax evasions of their own group $\alpha_{i}$ but crucially by the overall tax evasion $\alpha$, given inter-group spillovers.

${ }^{11}$ The hypothesis underlying Table 3 is that each agent $i$ evades a tiny fraction of the whole tax bill $\gamma$, with the population a continuum of size 1 . However, this is just a scale effect that does not affect any result in the equilibrium solution.

${ }^{12}$ If the government enforces taxes, the agents get a slice of the public goods, but this is marginal compared to the income gained by evading taxes. This is why there is always an ex-ante incentive to evade.
} 
3.2.2 A graphical analysis of the strategies within the game parameters

In this section we focus on a graphical analysis of the strategies for the government and the citizens, which are formulated in Table 3 .

The government will face three situations:

- if $\gamma-k-\alpha+\theta<0 \Rightarrow$ Anarchy is the optimal strategy

- if $\gamma-k-\alpha+\theta=0 \Rightarrow$ Anarchy or tax enforcement are equivalent

- if $\gamma-k-\alpha+\theta>0 \Rightarrow$ Tax enforcement is the optimal strategy

As illustrated in Figure 1, whenever the hyperplane is above the zero line the optimal strategy is to enforce tax collection, on the zero line there is an equivalence and below the optimal strategy is anarchy.

The citizens $(i=1,2)$ will face three situations if taxes are not enforced:

- if $\gamma_{i}-\left[t_{i}+\theta\right]+\alpha<0 \Rightarrow$ paying taxes is the optimal strategy

- if $\gamma_{i}-\left[t_{i}+\theta\right]+\alpha=0 \Rightarrow$ paying taxes or not is equivalent

- if $\gamma_{i}-\left[t_{i}+\theta\right]+\alpha>0 \Rightarrow$ not paying taxes is the optimal strategy

As shown in Figure 2, whenever the hyperplane is above the zero line the optimal strategy is not to pay, on the zero line there is an equivalence, and below it the optimal strategy is to pay. Figure 9 superimposes the two payoff functions.

The citizens $(i=1,2)$ will face three other situations in case of tax enforcement:

- if $-\left[t_{i}+\theta\right]+\alpha<0 \Rightarrow$ paying taxes is the optimal strategy

- if $-\left[t_{i}+\theta\right]+\alpha=0 \Rightarrow$ paying taxes or not is equivalent

- if $-\left[t_{i}+\theta\right]+\alpha>0 \Rightarrow$ not-paying taxes is the optimal strategy

In Figure 4, whenever the hyperplane is above the zero line the optimal strategy is not to pay, on the zero line there is an equivalence, and it below the optimal strategy is to pay. Figure 5 superimposes the two payoff functions.

\section{Perfect Information Game as the Benchmark Model}

Players' actions are strategic complements if they affect the best activity of others, and a positive externality if they affect the payoff structure of other players, who will be better off by increasing their own activity in turn (Cooper [1999]).

If we suppose that conditions (A1), (A2) and $(\mathrm{A} 3)$ are satisfied ${ }^{13}$ and suppose that a unique agent plays against the government, then the coordination failure among agents vanishes. This implies that $\alpha \in\{0,1\}, \alpha=\alpha_{1}+\alpha_{2}$ and no longer $\alpha \in[0,1]$, i.e the

\footnotetext{
${ }^{13}$ See appendix.
} 
Figure 1

Government

Government Payoff

theta-alpha-0.1

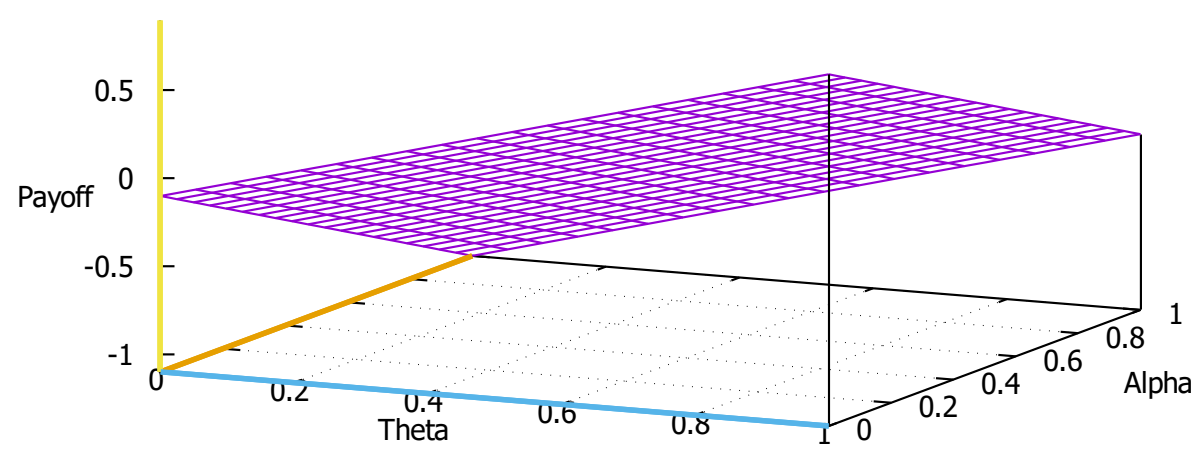

Government Payoff: $\gamma-k-\alpha+\theta=1-1.1-\alpha+\theta=\theta-\alpha-0.1$ 
Figure 2

Citizen: case 1

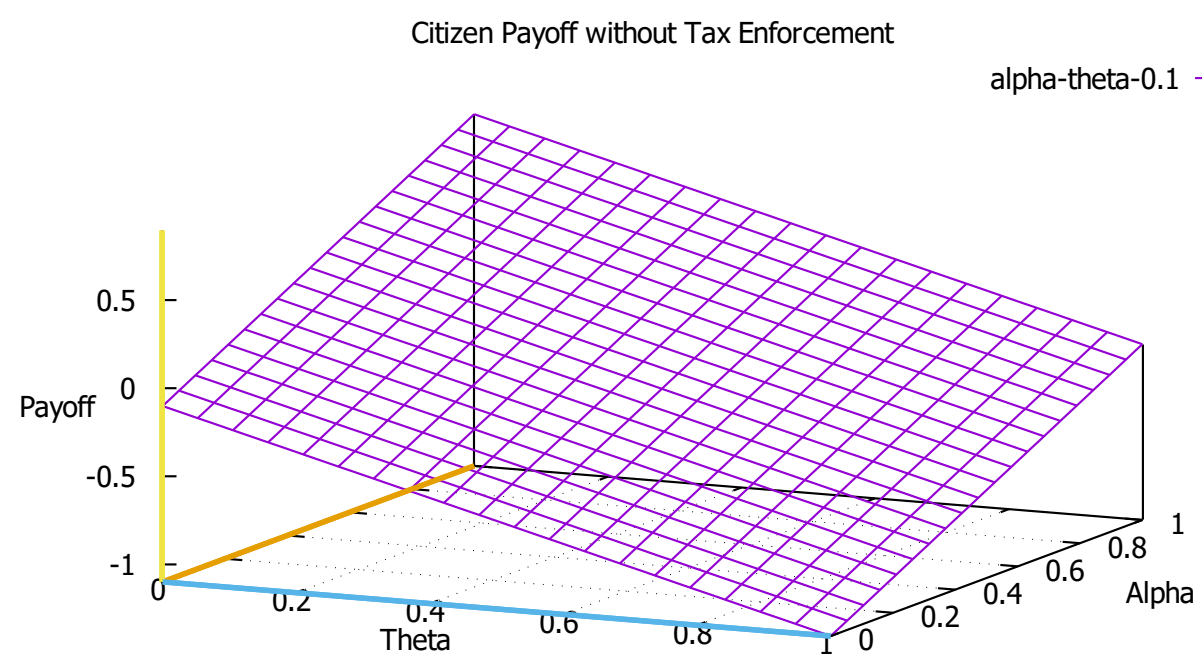

Agents' Payoff: $\gamma_{i}-\left[t_{i}+\theta\right]+\alpha=1-[1.1+\theta]+\alpha=\alpha-\theta-0.1$ 
Figure 3

Both: case 1

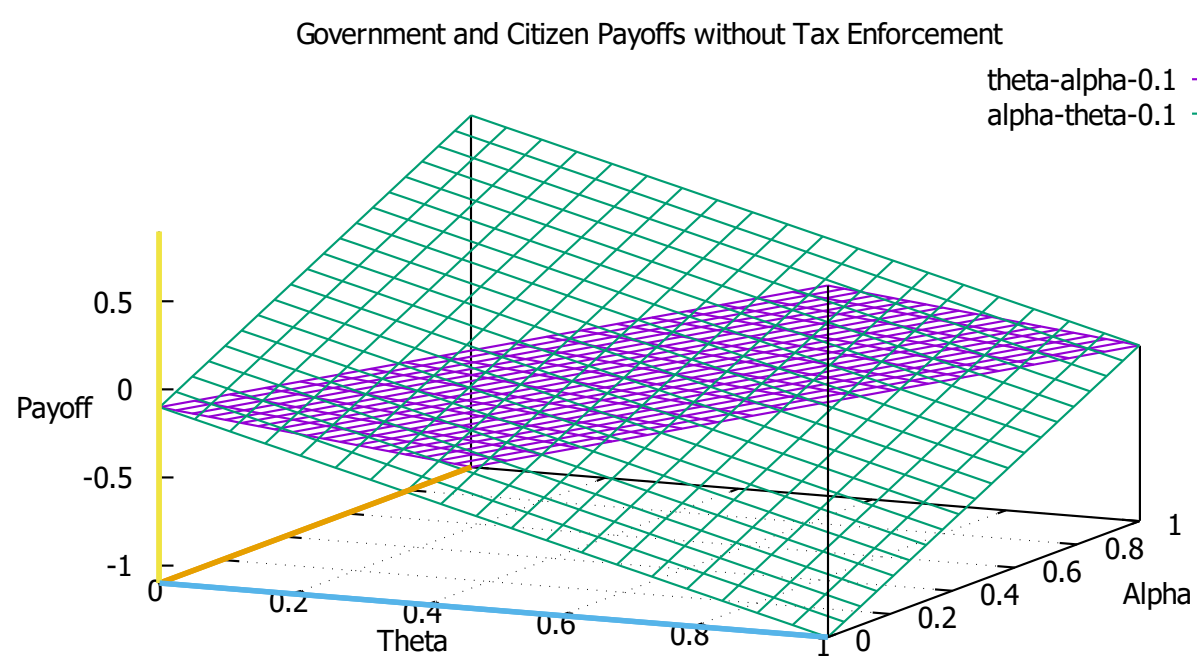

Government Payoff: $\theta-\alpha-0.1$; Agents' Payoff: $\alpha-\theta-0.1$ 
Figure 4

Citizen: case 2

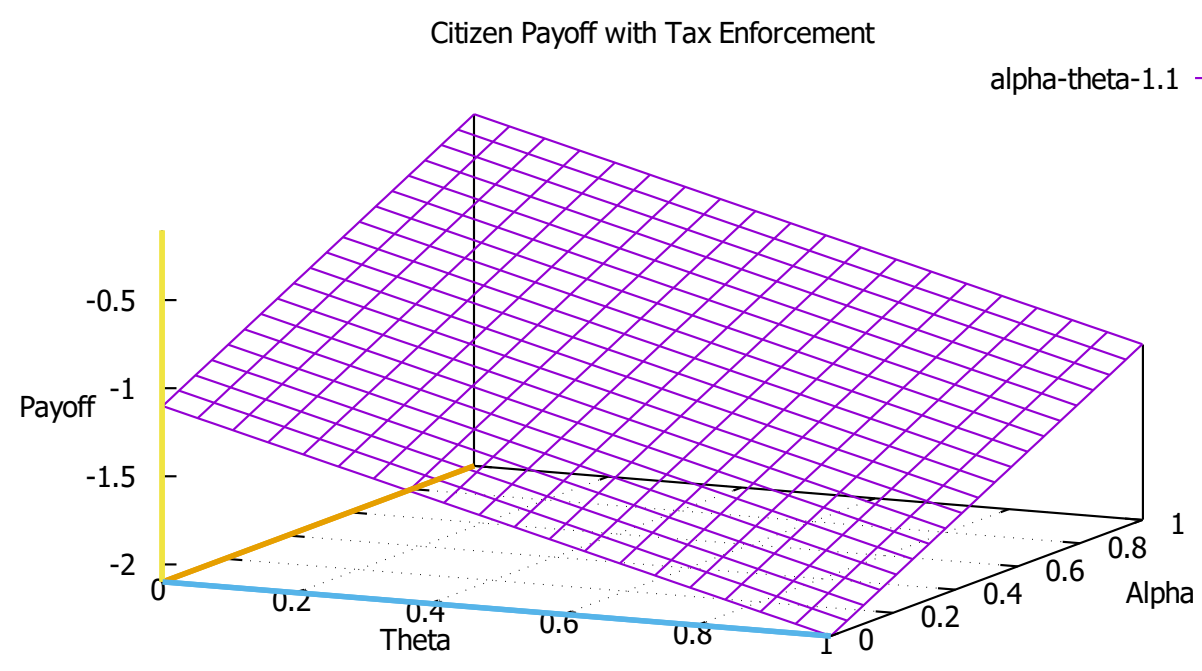

Agents' Payoff: $-\left[t_{i}+\theta\right]+\alpha=-[1.1+\theta]+\alpha=\alpha-\theta-1.1$ 
Figure 5

Both: case 2

Government and Citizen Payoffs with Tax Enforcement

theta-alpha- 0.1

alpha-theta-1.1

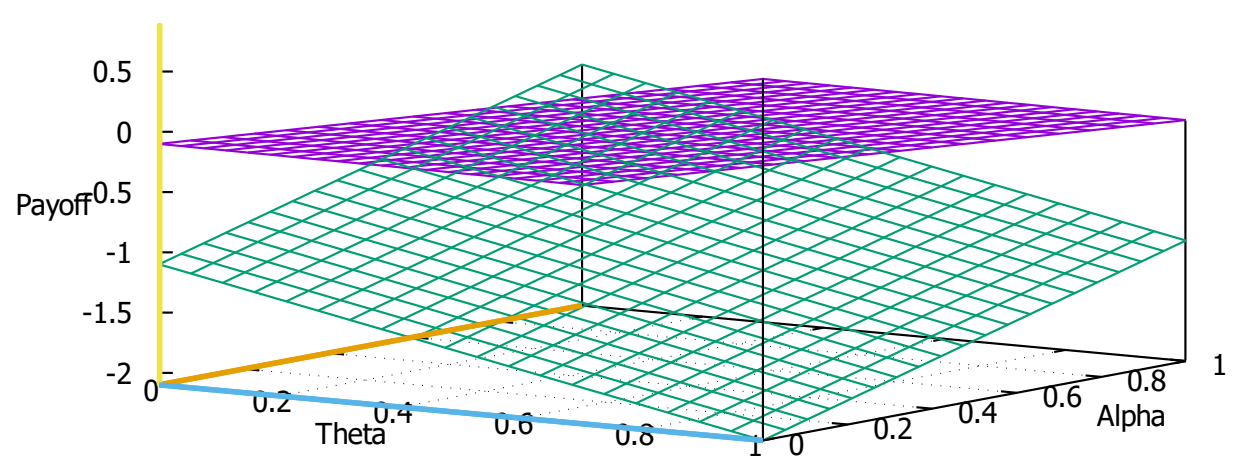

Government Payoff: $\theta-\alpha-0.1$; Agents' Payoff: $\alpha-\theta-1.1$ 
corner case in which all agents evade or pay taxes in a cooperative manner through a coalition. Lack of coordination failure implies lack of strategic uncertainty, while $\theta$ is predetermined and perfectly known by all players involved, both government and agents.

The equilibrium outcome will be different according to the time structure (simultaneous or sequential) of this two-player (one agent and the government) game with perfect information.

\subsection{Sequential Game}

Consider a sequential setting as depicted in figure 6, where the government plays after the citizens.

Proposition 1 In a sequential game in which a single agent faces no strategic uncertainty about institutional quality and therefore no coordination failure (i.e. one agent, sequential game with perfect information) there is one Sub-Game Perfect Nash Equilibrium (SPNE) where the agent evades taxes and there is no tax enforcement.

\section{Proof of Proposition 1}

We can write the game in extensive form by taking into account the out of equilibrium outcome in the case of only one agent (see footnote (7D)). Substituting for the functional form $c(\alpha, \theta)=\alpha-\theta$ the following game appears under conditions $\mathrm{A} 1)$, A2 and (A3):

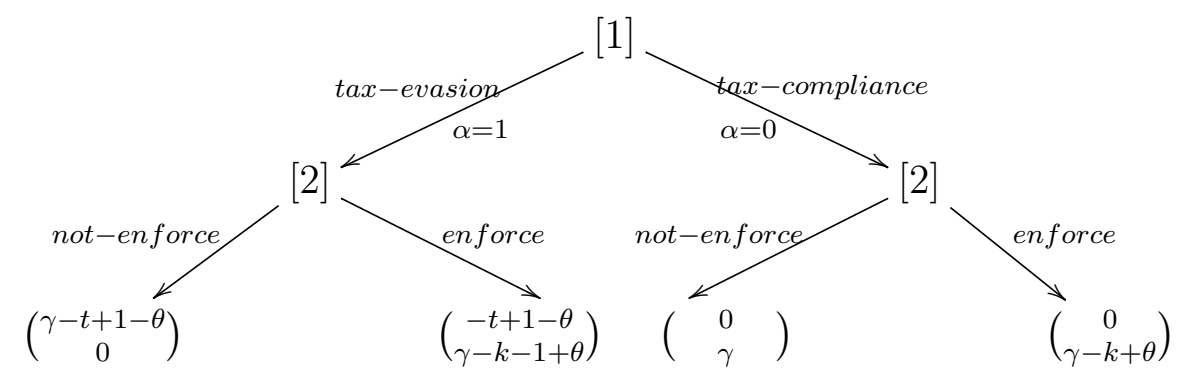

$\theta>k$ : by backward induction, the government will choose to give up tax enforcement if it expects the citizens to evade; the government will enforce if it expects them to pay. The agent, the first mover, will evade and the Sub-Game Perfect Nash equilibrium (Evade; Not-tax-enforcement) prevails. $\theta<k$ : the government will not enforce even if facing a tax-compliant agent, however the equilibrium will be again (Evade; Not-taxenforcement).

\subsection{Simultaneous Game}

Let us now suppose that the government and the citizens play simultaneously (Figure 7).

Proposition 2 In a simultaneous game in which a single 'body' of citizens faces no strategic uncertainty about institutional quality and therefore no coordination failure (i.e. 
Figure 6

Timing: Sequential Play

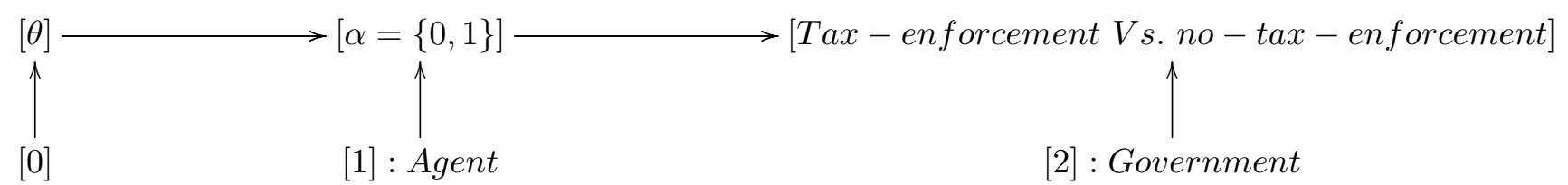

Figure 7

Timing: Simultaneous Play
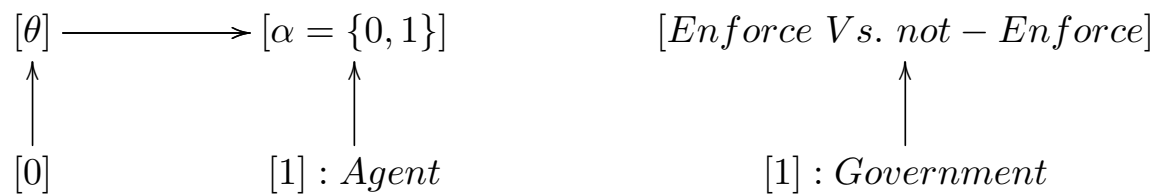

one agent, simultaneous game with perfect information) there are two Nash Equilibria for $k<\theta$ : one in which the government leaves the economy to anarchy and the agent evades taxes, and another in which taxes are enforced when the agent is tax-compliant.

\section{Proof of Proposition 2}

The game can be represented in strategic (normal) form again by taking into account the out of equilibrium outcome in the case of only one agent (see footnote (7)). Exploiting $c(\alpha, \theta)=\alpha-\theta$ we can summarise the strategies in the following payoffs matrix under conditions (A1), (A2) and (A3):

\section{Table 4}

Nash Equilibria in Strategic Form

\begin{tabular}{|r||r|r|}
\hline Agent $\backslash$ State & Enforce & Not-Enforce \\
\hline \hline Pay Taxes & $0 ; \gamma-k+\theta$ & $0 ; \gamma$ \\
\hline Evade & $-t_{i}+1-\theta ; \gamma-k-1+\theta$ & $\gamma_{i}-t_{i}+1-\theta ; 0$ \\
\hline
\end{tabular}

For $\theta>k$ two Nash equilibria emerge: (pay taxes; enforce taxes), (evade taxes; not-enforce taxes), whereas $\theta<k$ implies a unique equilibrium (evade taxes; not-enforce taxes). 
Figure 8

Timing: Sequential Play and Uncertainty

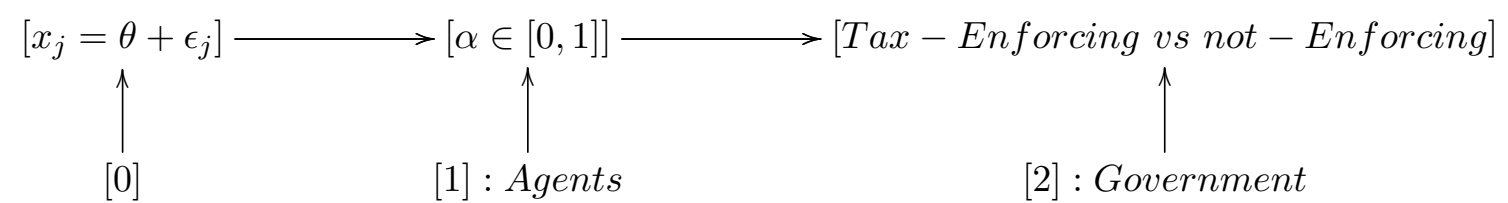

5 Imperfect Information Coordination Game: Modelling Tax Morale

In this section the analysis focuses on the model in which an idiosyncratic perception of a noisy signal of the institutional environment by each agent determines a blurred perception of other agents' actions. In other words, this model allows for heterogeneous perception of institutional quality and, as a direct consequence, of other players' actions. Following Luttmer and Singhal [2014] we posit this to be an appropriate way to capture as many channels as possible through which tax morale operates: intrinsic motivation (being accepted as a 'good' citizen), reciprocity, peer effects/social influences, culture and information imperfection/deviation from expected utility, as in Allingham and Sandmo [1972].

\subsection{Sequential Game}

Let us consider the sequential game first: each agent receives imperfect information about the economy's institutional quality and the government plays only after having observed $\alpha$ and $\theta$ as shown in Figure 8.

In other words, they receive idiosyncratic information about the economy's institutional type and quality, as in Morris and Shin [1998], namely agent $j$ receives the signal $x_{j}=\theta+\epsilon_{j}\left(x_{j}\right.$ distributed uniformly on $[\theta-\epsilon, \theta+\epsilon]$ with $\left.\epsilon>0\right)$. The signal $x$ is uniformly drawn on the interval $[\theta-\epsilon, \theta+\epsilon]$ with $\epsilon>0$. Conditions (A1), (A2), (A3) and (5) are satisfied.

Agents are conscious that the government's decision is based on the observed $\alpha$ and $\theta$. However $\alpha\left(\epsilon_{j}\right)$ depends on $\epsilon_{j}$, which is a random variable. To simplify the analysis we assume that each agent chooses according to an indicator function ${ }^{14}$.

$$
I_{x^{*}}\left(x_{j}\right)= \begin{cases}1 & \text { if } x_{j}<x_{j}^{*} \Rightarrow \text { Evade } \\ 0 & \text { if } x_{j} \geq x_{j}^{*} \Rightarrow \text { Pay Taxes }\end{cases}
$$

Proposition 3 In a sequential game in which a continuum of agents faces uncertainty about the economy's institutional quality and coordination failure among agents (sequential game with agents having imperfect information), there is one Sequential Nash

\footnotetext{
${ }^{14}$ It turns out that this is the "optimal" strategy: see Morris and Shin 1998.
} 
Equilibrium determined by

$$
\begin{gathered}
x_{i}^{*}=\theta^{*}+\frac{\epsilon\left[3 \gamma_{i}-2\left(k+t_{i}\right)\right]}{\gamma_{i}+2 t_{i}+1} \\
\theta^{*}=\frac{\epsilon[1+2(k-\gamma)]+\gamma(1+k-\gamma)-t+\frac{1}{2}}{\gamma+2 \epsilon+1}
\end{gathered}
$$

$i=1,2, \gamma=\gamma_{1}+\gamma_{2}=\left(w_{1}+w_{2}\right) \gamma$. Taxes are enforced if the value of $\theta$ is greater than $\theta^{*}$. Otherwise anarchy prevails.

\section{PROOF}

Government Action.

Using backward induction we start by looking at the decision rule of the government ${ }^{16}$, namely to enforce taxes if a sufficiently low number of agents evade, and viceversa to be content with anarchy if too many of them evade, where $c(\alpha, \theta)=\alpha-\theta^{17}$.

$$
\begin{aligned}
& \gamma-k-\alpha+\theta \geq 0 \Rightarrow \text { tax }- \text { enforcement } \\
& \gamma-k-\alpha+\theta<0 \Rightarrow \text { no-tax }- \text { enforcement }
\end{aligned}
$$

The proportion of criminals $\left(\alpha=\alpha_{1}+\alpha_{2}\right)$ whose actions are sufficient to compel the government to give up tax enforcement 18 is:

$$
\alpha(k, \theta, \gamma)= \begin{cases}0 & \text { if } 0 \leq \theta<k-\gamma \\ \gamma-k+\theta & \text { if } k-\gamma \leq \theta \leq \gamma+1-t\end{cases}
$$

The function $\alpha(k, \theta, \gamma)$ is increasing in $\theta$ (the higher the economy institutional quality, the easier the implementation of tax enforcement) and $\gamma$ (the higher the potential overall tax bill, the higher the effort in property rights protection and therefore redistribution into public goods). The function is negatively affected by the sunk cost $k$. The government observes the proportion of criminals in the economy and it compares it with $\alpha(k, \theta, \gamma)$, the maximum number of tax evaders before anarchy prevails. The higher the economys institutional quality, the fewer tax non-compliant agents and the higher the

\footnotetext{
${ }^{15}$ The population-wide fixed cost of tax-evasion could be considered a weighted average of the two groups costs; $\left[w_{1} /\left(w_{1}+w 2\right)\right] * t_{1}+\left[w_{2} /\left(w_{1}+w 2\right)\right] * t_{2}$

${ }^{16}$ For a similar modelling strategy see Bennet and Estrin 2013.

${ }^{17}$ The government is able to know the exact number of agents evading because it can measure tax revenues in the economy. Evasion prevents the government from applying taxes on the evaded (e.g. tunnelled abroad) money. Low tax collection is an indirect sign of high evasion. Furthermore, suppose the game could be repeated $n$ times: the agents and the government would learn about previous compliance levels and adapt their strategies accordingly. The process would be self-reinforcing. In other words, a multi-period model would have exactly the same qualitative results, but convergence to one equilibrium or another would be faster or slower, depending on the 'history' of previous rounds.

${ }^{18}$ The attribution of the equals sign to tax-enforcement or not is irrelevant. The probability that $\gamma-[k+\alpha-\theta]=0$ is zero.
} 
likelihood of tax enforcement. Vice-versa, the lower the institutional quality, the higher the number of non-compliant agents and the lower the likelihood of tax enforcement.

Citizens' Action.

Recalling the indicator function for each agent:

$$
I_{x^{*}}\left(x_{j}\right)= \begin{cases}1 & \text { if } x_{j}<x^{*} \Rightarrow \text { Evade } \\ 0 & \text { if } x_{j} \geq x^{*} \Rightarrow \text { Pay }\end{cases}
$$

Each agent receives a noisy signal about the economys institutional type and decides whether to pay taxes according to a simple threshold rule: strong signal, above $x^{*} \Rightarrow$ pay; weak signal, below $x^{*} \Rightarrow$ do not pay. The number of agents who will actually evade (call it $S(.,$.$) ) depends on the signal, which is uniformly distributed in the interval x_{i}$ distributed as $U[\theta-\epsilon, \theta+\epsilon]$ and on the institutional quality $\theta$. There are three distinct cases:

- $x^{*}>\theta+\epsilon \Rightarrow \theta<x^{*}-\epsilon$, the economys institutional quality is lower than the minimum signal any agent can see and everyone evades;

- $x^{*}<\theta-\epsilon \Rightarrow \theta>x^{*}+\epsilon$, the economys institutional quality is higher than the maximum signal any agent can see and all pay taxes;

- $x^{*} \in[\theta-\epsilon, \theta+\epsilon]$ the tax compliance choice derives from the expected value of $\alpha$, i.e. the overall level of evasion:

$$
\begin{gathered}
E(\alpha)=\frac{1}{2 \epsilon} \int_{\theta-\epsilon}^{\theta+\epsilon} I_{x^{*}}(x) d x=\frac{1}{2 \epsilon} \int_{\theta-\epsilon}^{x^{*}} I_{x^{*}}(x) d x+\frac{1}{2 \epsilon} \int_{x^{*}}^{\theta+\epsilon} I_{x^{*}}(x) d x= \\
\frac{1}{2 \epsilon}\left[x^{*}-(\theta-\epsilon)\right]=\frac{1}{2}-\frac{\left(\theta-x^{*}\right)}{2 \epsilon}
\end{gathered}
$$

The share of agents evading taxes is:

$$
S\left(\theta, I_{x^{*}}\left(x_{j}\right)\right)=\left\{\begin{array}{lll}
1 & \text { if } x^{*}>\theta+\epsilon & \theta<x^{*}-\epsilon \\
\frac{1}{2}-\frac{1}{2 \epsilon}\left(\theta-x^{*}\right) & \text { if } x^{*} \in[\theta-\epsilon, \theta+\epsilon] & \theta \in\left[x^{*}-\epsilon, x^{*}+\epsilon\right] \\
0 & \text { if } x^{*}<\theta-\epsilon & \theta>x^{*}+\epsilon
\end{array}\right.
$$

\subsubsection{Equilibrium}

The two functions $\alpha(k, \theta, \gamma)$ (increasing in $\theta)$ and $S\left(\theta, I_{x^{*}}\left(x_{j}\right)\right)$ (decreasing in $\theta$ ) cross at the 'equilibrium value' $\theta^{*}$ :

Following Obstfeld [1996], Morris and Shin [1998] and applying the condition found in section 7, we can divide the parameter $\theta$ space into three intervals:

- anarchy/hell $\theta \in[0, \underline{\theta}]$. The condition under which anarchy is the dominant strategy for the government is $k+\alpha-\underline{\theta}>\gamma \quad \forall \alpha \Rightarrow \underline{\theta}=(k-\gamma \mid \alpha=0)>0 \Rightarrow k>\gamma$ as in the worst economy institutional environment case. Below $\underline{\theta}$, not to enforce taxes is the dominant strategy for the government; 
Figure 9

Equilibrium: $\theta^{*}$

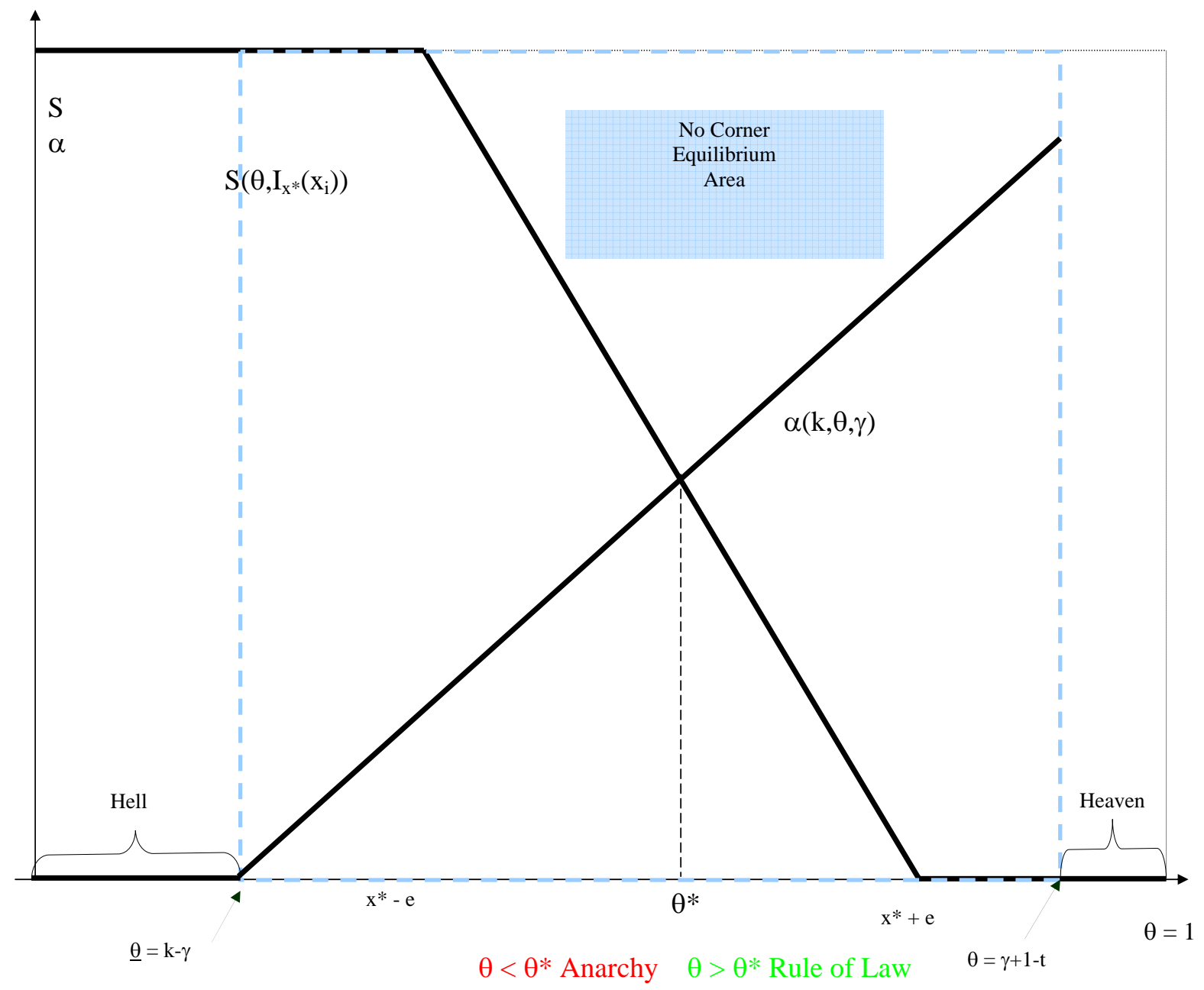


- tax enforcement $\theta \in[\bar{\theta}, 1]$. The condition under which paying taxes is a dominant strategy for the agents is $\gamma-t+\alpha-\bar{\theta}<0 \quad \forall \alpha \Rightarrow \bar{\theta}=(\gamma+1-t \mid \alpha=1)>$ $0 \Rightarrow t>\gamma$ as in the best economy institutional environment case. Above $\bar{\theta}$, agents' costs of evading outweigh the benefits, so paying taxes becomes their dominant strategy;

- indetermined $\theta \in[\underline{\theta}, \bar{\theta}]$.

No strictly dominant strategies emerge if

$$
\theta \in[\max \{0, k-\gamma\}, \min \{1, \gamma+1-t\}]
$$

$$
\begin{gathered}
\gamma-k+\theta=\frac{1}{2}-\frac{1}{2 \epsilon}\left(\theta-x^{*}\right) \Rightarrow \\
\theta^{*}=\frac{1}{1+2 \epsilon}\left\{x^{*}+\epsilon[1+2(k-\gamma)]\right\} \\
\left\{\begin{array}{cc}
\theta>\theta^{*} \Rightarrow \alpha(k, \theta, \gamma)>S\left(\theta, I_{x^{*}}\left(x_{j}\right)\right) & \text { enforcement } \\
\theta<\theta^{*} \Rightarrow \alpha(k, \theta, \gamma)<S\left(\theta, I_{x^{*}}\left(x_{j}\right)\right) & \text { Not - enforcement }
\end{array}\right.
\end{gathered}
$$

The government decides in favour of tax enforcement if the proportion of agents evading $(\mathrm{S})$ is lower than the maximum bearable percentage $(\alpha)$. The opposite happens if the inequality is reversed and anarchy prevails (see Figure $9{ }^{19}$.

Citizens payoff. We start from the payoff in the event of tax evasion, which endogenously depends on the subsequent action of the state with regard to tax enforcement.

$$
h\left(\theta, x^{*}\right)=\left\{\begin{array}{llll}
\alpha-\theta-t_{i} & ; \theta>\theta^{*} & ; \alpha(\theta)>S\left(\theta, I_{x^{*}}(x)\right) & \text { enforcement } \\
\gamma+\alpha-\theta-t_{i} & ; \theta<\theta^{*} & ; \alpha(\theta)<S\left(\theta, I_{x^{*}}(x)\right) & \text { anarchy }
\end{array}\right.
$$

$h\left(\theta, x^{*}\right)$ represents the realised payoffs in the event of full common knowledge (no uncertainty). On the contrary, agents observe an idiosyncratic noisy signal, making their evade-or-pay decision on the basis of $E_{i}\left\{h\left(\theta, x^{*}\right) \mid x_{j}\right\} \lessgtr 0$. Solving for the expected value of the indifferent agent, we will show that $x^{*}$ is indeed unique and that the strategy summarised by the indicator function $I_{x^{*}}(x)$ is the optimal strategy.

Every agent within each group type $i=1,2$ is identical and knows that the other agents face exactly the same problem, so a representative agent (subscript $j$ dropped for simplicity) will compute the following expected value, knowing that the signals are distributed around $x_{j}$ distributed as $U[\theta-\epsilon, \theta+\epsilon] \Rightarrow \theta \in[x-\epsilon, x+\epsilon]$ :

\footnotetext{
${ }^{19}$ If the $\theta^{*}$ was implicitly derived through $\alpha(k, \theta, \gamma)=S\left(\theta, I_{x^{*}}(x)\right)$, then it could be shown that $0<\frac{\partial \theta^{*}}{\partial x^{*}}<1$ : any increase in the agents' threshold rule positively affects (less than proportionally) the economy institutional quality threshold under which there is tax evasion.
} 


$$
\begin{gathered}
\frac{1}{2 \epsilon} \int_{x_{i}-\epsilon}^{\theta^{*}}\left[\gamma_{i}+\alpha-\theta-t_{i}\right] d \theta+\frac{1}{2 \epsilon} \int_{\theta^{*}}^{x_{i}+\epsilon}\left[\alpha-\theta-t_{i}\right] d \theta= \\
\frac{1}{2 \epsilon}\left[\int_{x_{i}-\epsilon}^{x_{i}+\epsilon}\left[\alpha-\theta-t_{i}\right] d \theta+\gamma_{i} \int_{x_{i}-\epsilon}^{\theta^{*}} d \theta\right]= \\
\frac{1}{2 \epsilon}\left[\int_{x_{i}-\epsilon}^{x_{i}+\epsilon}\left[\alpha-\theta-t_{i}\right] d \theta+\gamma\left(\theta^{*}-x_{i}+\epsilon\right)\right]
\end{gathered}
$$

The indifferent agent is the one observing exactly $x^{*}$ (this agent exists due to the uniform distribution hypothesis of the noisy signals) and she neither gains nor loses by evading, in other words $E_{j}\left\{h\left(\theta, x^{*}\right) \mid x_{j}^{*}\right\}=u\left(x_{j}^{*}, x^{*}\right)=0$.

$$
\frac{1}{2 \epsilon}\left[\int_{x_{i}^{*}-\epsilon}^{x_{i}^{*}+\epsilon}\left[\alpha-\theta-t_{i}\right] d \theta+\gamma_{i}\left(\theta^{*}-x_{i}^{*}+\epsilon\right)\right]=0
$$

Solving for $\theta^{*}$ and exploiting 7 and $\left[w_{1} /\left(w_{1}+w 2\right)\right] * t_{1}+\left[w_{2} /\left(w_{1}+w 2\right)\right] * t_{2}$ :

$$
\begin{gathered}
x_{i}^{*}=\theta^{*}+\frac{\epsilon\left[3 \gamma_{i}-2\left(k+t_{i}\right)\right]}{\gamma_{i}+2 \epsilon+1} \\
\theta^{*}=\frac{\epsilon[1+2(k-\gamma)]+\gamma(1+k-\gamma)-t+\frac{1}{2}}{\gamma+2 \epsilon+1} .
\end{gathered}
$$

Q.E.D.

\subsubsection{The limit case with no uncertainty}

We now refer now to the case when informational noise converges to zero, $\epsilon \rightarrow 0$.

COROLLARY 1 In a simultaneous (sequential) game with no uncertainty about the economy's institutional quality (i.e. $\epsilon \rightarrow 0$ ) and coordination failure among agent $\$ 20$, there is one Sub-Game Perfect Nash equilibrium (one Sequential Nash Equilibrium) determined by:

$$
x^{*}=\theta^{*}=\frac{\gamma(1+k-\gamma)-t+\frac{1}{2}}{\gamma+1}
$$

Taxes are enforced if the value of $\theta$ selected by nature is greater than $\theta^{*}$, otherwise anarchy prevails.

\footnotetext{
${ }^{20}$ This is the reason why the group-specific subscripts $i=1,2$ disappear altogether.
} 
Proof This is the case in which agents observe $\theta$ perfectly and choose according to the known $\theta$ : from propositions (3) and (1) the function describing the share of agents not paying would become a step function $S\left(\theta^{*}, I_{x^{*}}(\theta)\right)$, i.e. $\epsilon \rightarrow 0 \Rightarrow x^{*}=\theta^{*}$,

$$
S\left(\theta, I_{x^{*}}(\theta)\right)= \begin{cases}1 & \text { if } x^{*}=\theta^{*}>\theta \\ 0 & \text { if } x^{*}=\theta^{*}<\theta\end{cases}
$$

and (11) immediately follows.

Q.E.D.

\subsubsection{Comparative Statics}

The derivatives of the threshold for the signal $\left(x_{i}^{*}\right)$ and the threshold for the economy's institutional quality $\left(\theta^{*}\right)$ with respect to $\epsilon$ (the degree of uncertainty), $\gamma_{i}$ (the value of the tax revenue in the economy), $k$ (the sunk cost of the government enforcing the rule of law) and $t_{i}$ (the fixed cost of evading) together provide the mapping of the comparative statics exercise on the model, entailing the following important corollary:

COROLlaRY 2 The increase in uncertainty $(\epsilon)$ and tax enforcement fixed costs ( $k$ ) expand the equilibrium area (likelihood) for anarchy, whilst increases in asset value, the tax revenue $\lambda^{21}$ and evading costs $t_{i}$ expand the equilibrium area (likelihood) for tax enforcement.

Proof See Appendix.

Predation by the government: the role of $\gamma$ and distributional effects.

The parameter $\gamma$ has so far been interpreted as public spending from the tax revenues. However, government action in enforcing tax collection on the agents' assets can be motivated by expropriation and rent-seeking. If citizens know that tax enforcement might well turn out to be an ex-post predation by the government instead of a means of redistribution in the form of public goods, then they will evade as much as possible and leave the government with a low ex-ante incentive to actually protect property rights themselves by enforcing taxes. This might well happen in the presence of politicians who are not credible in their commitment to non-expropriatory action by the state they represent. In other words, the corner solution of $\gamma=0$ always leads to anarchy (vicious cycle), as would reasonably be expected.

By the same token, if the state is going to redistribute the entire value of assets $(\gamma)$ and this value is sufficiently high, agents expect the redistribution of $\gamma$ in the form of public goods and services by tax enforcement (virtuous cycle). In this case, agents anticipate this effect and refrain from tax evasion.

The relative weight of revenues $\left(w_{12}\right)$ in the two groups plays a particularly key role in the redistribution of such revenues. Suppose that the two weights represent two unequal fractions of the population: ordinary citizens as type 1 and oligarchs as type

\footnotetext{
${ }^{21}$ This will hold if $\gamma$ is sufficiently large.
} 
2. We would then expect the revenues related to the former to be greater than those related to the latter. This in turn implies $\gamma_{1}>\gamma_{2}$ and therefore $x_{1}^{*}<x_{2}^{*}$, pushing type 1 citizens to evade relatively less taxes than type two, as we actually observe in many countries (see Kleven, Knudsen, Kreiner, Pesersen and Saez 2011). Unfortunately the higher this discrepancy in tax evasion, the higher the burden of taxes on the type 1 citizens ${ }^{22}$ and the gain for type 2 .

Costs of enforcement and tax evasion: the role of $k$ and $t_{i}$.

High sunk costs associated with tax enforcement increase the likelihood of anarchy and high fixed costs associated with tax evasion induces lower evasion and a higher probability of tax enforcement in the first place. Let us assume that type 1 citizens bear a higher cost $\left(t_{12}\right)$ of tax evasion than type 2 , given that by nature, third-party reported income is more easily detected and punished than self-reported income. Based on Corollary 2, this again implies $\gamma_{1}>\gamma_{2}$ and therefore $x_{1}^{*}<x_{2}^{*}$, inducing type 1 citizens to evade relatively less taxes than type 2 .

This reasoning leads to a new corollary, which focuses on the distributional impact of the model:

COROLlaRY 3 If there is a proportional relationship between the group size and its cost of evasion $\frac{\partial t_{i}}{\partial w_{i}}>q^{23}$ and corollary 2 holds, then the higher the size of a group vis-a-vis the other $w_{1}>>w_{2}$, the lower the attitude in group-specific tax evasion $\alpha_{1}<<\alpha_{2}$, ceteris paribus. Therefore the bigger group bears a higher tax burden vs. the smaller one.

PROOF From corollary 2

$$
\begin{gathered}
\frac{\partial x_{i}^{*}}{\partial \gamma_{i}}=\frac{\left[2 \epsilon\left(1+k+t_{i}+\epsilon\right)+k+t_{i}+1 / 2-\gamma_{i}\left(2+\gamma_{i}+4 \epsilon\right)\right]}{\left(\gamma_{i}+2 \epsilon+1\right)^{2}}<0 \\
\frac{\partial \theta^{*}}{\partial \gamma}=\frac{1 / 2+k+t-\epsilon[4(\epsilon+\gamma)+1]-\gamma(\gamma+2)}{(\gamma+2 \epsilon+1)^{2}}<0 ; \\
\frac{\partial x_{i}^{*}}{\partial t_{i}}=-\frac{2 \epsilon+1}{\left(\gamma_{i}+2 \epsilon+1\right)}<0, \frac{\partial \theta^{*}}{\partial t}=-\frac{1}{\gamma+2 \epsilon+1}<0 ; \\
w_{1}>w_{2} \Longrightarrow \gamma_{1}>\gamma_{2} ; t_{1}>t_{2} \Longrightarrow x_{1}^{*}<x_{2}^{*} ; \Longrightarrow \alpha_{1}^{*}>\alpha_{2}^{*}
\end{gathered}
$$

Two Corner cases: Russia vs. Slovak Republic. Looking back at Table1, Russia can be seen as a clear example of a country with poor institutional quality and high tax evasion, where the divide between ordinary citizens and oligarchs is exacerbated. Applied to

\footnotetext{
${ }^{22}$ For an extension to more than two type of citizens see appendix.

${ }^{23}$ Third-reporting group represents a higher proportion of the total tax revenue and is characterised by a higher probability (and cost) to be caught (Allingham and Sandmo [1972] when evading, due to their limited margin of actions (Kleven, Knudsen, Kreiner, Pesersen and Saez |2011]).
} 
Table 5

Citizen Groups relative tax evasion

\begin{tabular}{l|l|l|l|l|l}
\hline Group $i$ & \multicolumn{5}{|c}{ Parameters' Space } \\
& Tax regime & $\begin{array}{l}\text { Groups' } \\
\text { Weight }\end{array}$ & $\begin{array}{l}\text { Tax } \\
\text { Revenue }\end{array}$ & $\begin{array}{l}\text { Tax evasion } \\
\text { Cost }\end{array}$ & $\begin{array}{l}\text { Tax evasion } \\
\text { Attitude }\end{array}$ \\
\hline Type-1 & third-party reporting & $w_{1}\left(>w_{2}\right)$ & $\gamma_{1}\left(>\gamma_{2}\right)$ & $t_{1}\left(>t_{2}\right)$ & $\alpha_{1}^{*}\left(<\alpha_{2}^{*}\right)$ \\
Type-2 & self-reported income & $w_{2}\left(<w_{1}\right)$ & $\gamma_{2}\left(<\gamma_{1}\right)$ & $t_{2}\left(<t_{1}\right)$ & $\alpha_{2}^{*}\left(>\alpha_{1}^{*}\right)$ \\
\hline
\end{tabular}

our model, Russia would be converging towards a corner solution where, for example, $t_{2}=0$. The burden on type 1 citizens becomes very high and overall tax evasion (by the oligarchs) is endemic. On the opposite side, referring to the same table, the Slovak Republic cane be seen as a country with good institutional quality and relatively low tax evasion. In this case a virtuous cycle may lead to even lower overall tax evasion and less distributional burden.

The role of information: $\epsilon$.

The model of this paper extends the Morris and Shin 1998 model. The agents' evasion cost is endogenously determined by the overall tax evasion, in line with models of the rule of law in Cooter [1996] and Roland and Verdier [2003]. There is a "positive" externality if agents evade; in other words, the cost of evasion inversely depends on $\alpha$. Coordination failure among agents and uncertainty are deeply connected. If agents could coordinate, e.g. by forming a coalition in a cooperative game framework, they could pool their idiosyncratic pieces of information together and overcome the individual uncertainty for the sake of common knowledge. Vice-versa, in a non-cooperative and more realistic imperfect information model, each opportunistic agent exploits idiosyncratic pieces of information to maximise her own utility vis-à-vis the behaviour of all other players, and then coordination failure occurs.

This paper shows that coordination failure among agents is always conducive to a unique equilibrium, regardless of the time structure and the existence of uncertainty $\grave{a}$ la Morris and Shin [1998]. The novel contribution of this paper is rooted in enriching our understanding of the role of uncertainty versus coordination failure in a model that encompasses tax enforcement, tax compliance and tax morale (see also Cooter [1996], Roland and Verdier 2003] and Hoff and Stiglitz 2004a]).

When uncertainty is high, that is, when many agents receive signals about institutional quality that are far away from the true value, this causes the proportion of criminals to rise. This holds true notwithstanding a decrease in $x^{*}$, an effect that would per se increase the probability of tax enforcement, but it is not enough to counteract the simultaneous increase of $\epsilon$, i.e. the uncertainty area.

Equations 9 and 10 allow for the computation of the level of uncertainty, call it $\bar{\epsilon}$, over which there is anarchy and under which there is tax enforcement, given the other parameters and exploiting condition (5): 


$$
\begin{gathered}
\bar{\epsilon}=\frac{\theta(1+\gamma)-\gamma(1+k-\gamma)+t-\frac{1}{2}}{1+2(k-\gamma-\theta)} \\
\bar{\epsilon}=\frac{\theta(1+\gamma)-\gamma(1+\underline{\theta})+t-\frac{1}{2}}{1+2(\underline{\theta}-\theta)}
\end{gathered}
$$

This critical level of uncertainty is an increasing function of the quality of institutions $\theta$, the sunk cost of evading $t$, while it decreases with $k$, the cost of enforcing the tax collection. In a country like Russia where the combination of these parameters is not favourable (bad bureaucracy and bad institutions), even a low level of uncertainty can lead to anarchy and information becomes crucia24. On the contrary, within a solid economic context (good enforcement by bureaucracy, no expropriation risk, good general institutional quality) like the Slovak Republic, the above threshold is pushed upward, and the likelihood of ending up in a bad equilibrium is extremely low.

\section{Tax enforcement and information in transition economies.}

This model allows for normative policy implications in terms of what is needed to counteract the risk of anarchy, where many agents evade and the government does not enforce tax collection or even expropriate (see for a comparison the conclusions in Traxler [2010]). If the economy is slow as far as the implementation of reform is concerned (low economy institutional environment), there are few options in order to lead the economy on a virtuous path. This is probably the case in countries where institutions change very slowly (Roland [2001]; Roland [2004]) and the economy is not recovering fast enough from a negative shock of the transition period, a sort of hysteresis effect. In other words, in economies where institutional quality is poor, and hence expectations of the rule of law being implemented via tax enforcement are low, the anarchy outcome is the most likely equilibrium result.

Russia and Ukraine register high corruption rates and large shadow economies. These countries' respective governments still struggle to enforce tax collection, i.e. enforcement implementation is weak and there is little emphasis on the importance of cooperation or property rights protection.

The role of information among community members has also been analysed by Kandori [1992, positing that each agent carries a label and the community somehow 'marks' deviators. Under the assumption that social norms dictate that an individual should not cooperate if the potential partner is labelled a deviator, nobody has an incentive to deviate from the equilibrium path when the punishment is severe enough. If an individual is likely to deal with many deviators in the future, the punishment might be costly to carry out and this may destroy the incentive for them to cooperate. When the information available depicts a community in which illegal behaviour is likely to occur without community punishment, the tendency to respect social norms is low because

\footnotetext{
${ }^{24}$ On the role of information within a model where corrupt officials can take bribes ex-ante to reduce red tape, or where corrupt bureaucrats can create more red tape in order to reveal information and extort bribes, see Guriev 2004.
} 
community enforcement is weak. This is a compelling explanation, but it can be applied to transition economies only partially, where the phenomenon of 'community labelling' (in the form of reputation, membership, citizenship, credit cards, etc.) could be weak or non-existent. In this paper, we assume that information comes from a different source and is therefore transmitted via specific channels.

The government and civil society must seize any chance of reciprocal collaboration, knowing that cooperative action could lead to 'social surplus' (Weingast [1997]). In other words, the big push argument à la Murphy, Schleifer and Vishny |1989| in this context would be justified by the need to escape from the coordination failure characterising the collective action problem. In this respect, reducing any distorting information signals, encouraging free media and the existence of pluralistic and independent ${ }^{25}$ sources of information are key ${ }^{26}$.

Black, Kraakman and Tarassova [2000] summarise this idea in a very compelling way

In Russia “[...] company managers and kleptocrats opposed efforts to strengthen or enforce the capital market laws [...] and what they didn't want, they didn't get."

On a more positive note, by recalling the results in Hoff and Stiglitz 2004a we can assert that there are conditions favouring the emergence of tax enforcement: when the beneficiaries of privatisation are too weak individually to obtain privileged property rights protection from the state, they may however be aware that they are strong enough collectively to secure the rule of law when there is sufficient strength in the political demand for its enforcement.

\section{Concluding Remarks}

At the beginning of transition from central planning to market-based economy, transition countries witnessed the separation between control and ownership of the assets obtained through the privatisation process (Hoff and Stiglitz [2008]). The state confronted a context of tax evasion, asset stripping, privatisation in favour of only a few big businessmen, whisking and tunnelling of capital, and difficulties in enforcing contracts. After almost three decades of transition, these economies are still characterised by widespread shadow economies and by limited or 'selective' tax enforcement.

This paper has focused on the reasons behind this phenomenon by drawing upon Traxler [2010]s idea of 'conditional cooperative taxpayers', expanding upon the Hoff and Stiglitz [2004a model of institutionally weak economies, and finally by exploiting the global games approach (Morris and Shin [1998]) to solve a coordination game with

\footnotetext{
${ }^{25}$ See for example the international Russian digital TV channel, Russia Today, which is still solidly in government hands.

${ }^{26}$ The state, whose information on the parameter $\theta$ is perfect, could signal that institutions are strong and that it will be bold in tax enforcement, ipso facto increasing the probability of law enforcement. However, this signal may or may not be credible. I thank Jan Fidrmuc for pointing out the informed state's signalling option.
} 
imperfect information. The quality of institutions and the information on such quality jointly determine whether anarchy or tax enforcement prevail. In this model, information conveys a noisy signal to agents, whose choice is based on the expectation of other players' actions. Most agents will evade taxes if they expect many others to do the same. Vice-versa, most agents will pay taxes if they expect few others to evade. These tendencies prevail among both ordinary citizens and oligarchs even if, all else being equal, the latter are more likely to evade than the former. Countries in the reform process with a propensity for good institutions will guarantee tax enforcement and will therefore be able to reduce distributional injustice. Laggard countries, by contrast, will be confronted with anarchy and higher polarisation of wealth, partly because the group of self-reporting citizens will be the first to converge towards evasion and personal gains.

This paper does show that high uncertainty and sunk costs of tax enforcement have an overall negative effect on tax compliance, pushing the economy towards an anarchy equilibrium, whereas a higher value of tax revenues needed for public goods and services has a positive impact on the decision to implement enforcement. Citizens characterised by third-party reporting will evade taxes less than those who self-report their income citizens in an equilibrium, yet they will bear a higher cost of the distributional burden of high tax evasion in poor institutional quality countries.

The stylised framework of this paper reflects the period of uncertainty and poor commitment to reform in some transition countries, where property rights protection is low, despite a relatively advanced stage of convergence to pro-market reforms. In a context of sound institutional quality, the policy implication would be to require the government to intervene in order to decrease uncertainty and promote the dissemination of information, such as by guaranteeing the presence of a pluralistic free press. Conversely, in a context of poor institutional quality, reducing uncertainty would not be sufficient. The model proposed in this paper provides a representation of the situation experienced by transition countries at a relatively advanced stage of convergence to pro-market economic institutions but lacking effective property rights protection. This combination could endogenously lead to low tax enforcement, tax compliance and tax morale.

The recognition that a country could be bound to underdevelopment in the long run if burdened by a potentially predatory state and weak rule of law finds some consensus. The results of this paper can be applied to a wide range of economic situations within the heterogeneous context of transition economies as well as developing countries.

\section{Appendix}

\section{Parameter boundary conditions}

- $\theta=0$, lowest institutional quality: when the economy lies at the minimum "institutional type" $(\theta=0)$, the number of tax criminals is irrelevant. Even with $\alpha=0$, the cost for the government is higher than the gain of tax enforcement and therefore the government's payoff would be $\gamma-k-\alpha+0<0 \quad \forall \alpha \Rightarrow \gamma-k-0+0<$ $0 \Rightarrow k>\gamma$ 
- $\alpha=1$, all agents evade. In the case in which all agents evade, the government has a negative payoff despite the fact that the economy type could be the best $(\theta=1)$, and therefore the government's payoff would be $\gamma-k-1+\theta<0 \quad \forall \theta \Rightarrow$ $\gamma-k-1+1<0 \Rightarrow k>\gamma$

- $\theta=1$, best institutional quality: when the economy has the maximum "institutional type" $(\theta=1)$, no matter how many agents decide to evade (even $\alpha=1$ ), the fixed cost of tax evasion will always outweigh the related gain, and the agents' payoff would be $\gamma-t+\alpha-1<0 \quad \forall \alpha \Rightarrow \gamma+1-1-t<0 \Rightarrow t>\gamma$.

Exploiting these boundary conditions and knowing that both $\alpha$ and $\theta$ bounded in the $[0,1]$ interval we can also show that $k-\gamma \leq 1, t-\gamma \leq 1, \gamma+1-t \leq 1, \gamma+1-k \leq 1$, rearranging in three conditions:

$$
\begin{array}{r}
0<\underline{\theta}<1 \Leftrightarrow \gamma \leq k \leq \gamma+1 \\
0<\bar{\theta}<1 \Leftrightarrow \gamma \leq t \leq \gamma+1 \\
\underline{\theta}<\bar{\theta} \Leftrightarrow k+t-1<2 \gamma
\end{array}
$$

Proof of Corollary 2

$$
\begin{gathered}
\frac{\partial x_{i}^{*}}{\partial \epsilon}=\frac{\gamma_{i}\left[3 \gamma_{i}-2\left(t_{i}+k\right)\right]}{\gamma_{i}+2 \epsilon+1}<0, \frac{\partial \theta^{*}}{\partial \epsilon}=\frac{2(k+t)-3 \gamma}{(\gamma+2 \epsilon+1)^{2}}>0 ; \\
\frac{\partial x_{i}^{*}}{\partial \gamma_{i}}=\frac{\left[2 \epsilon\left(1+k+t_{i}+\epsilon\right)+k+t_{i}+1 / 2-\gamma_{i}\left(2+\gamma_{i}+4 \epsilon\right)\right]}{\left(\gamma_{i}+2 \epsilon+1\right)^{2}}<0, \\
\frac{\partial \theta^{*}}{\partial \gamma}=\frac{1 / 2+k+t-\epsilon[4(\epsilon+\gamma)+1]-\gamma(\gamma+2)}{(\gamma+2 \epsilon+1)^{2}}<0 ; \\
\frac{\partial x_{i}^{*}}{\partial k}=\frac{\gamma_{i}}{\left(\gamma_{i}+2 \epsilon+1\right)}>0, \frac{\partial \theta^{*}}{\partial k}=\frac{2 \epsilon+\gamma}{\gamma+2 \epsilon+1}>0 ; \\
\frac{\partial x_{i}^{*}}{\partial t_{i}}=-\frac{2 \epsilon+1}{\left(\gamma_{i}+2 \epsilon+1\right)}<0, \frac{\partial \theta^{*}}{\partial t}=-\frac{1}{\gamma+2 \epsilon+1}<0
\end{gathered}
$$

The inequalities exploit the conditions $\gamma<k<\gamma+1, \gamma<t<\gamma+1$ and $\gamma>>0$ is not too small. Equations A5 and A6 are valid, respectively, if:

$$
\begin{gathered}
\gamma+(2 \epsilon+1)>\sqrt{6\left(\frac{1}{2}+\epsilon\right)^{2}+(2 \epsilon+1)(k+t)} \\
\gamma+(2 \epsilon+1)>\sqrt{3\left(\frac{1}{2}+\epsilon\right)+(k+t)}
\end{gathered}
$$

The right hand side of equation A10 is always larger than the right hand side of equation A11, hence the former is sufficient for both inequalities A5 and A6 to hold. 


\section{Extension of Corollary 3: $n$ number of groups}

COROLlary 4 If the society is divided in $n$ groups whose relationship between a group size and its cost of evasion is directly proportional $\frac{\partial t_{i}}{\partial w_{i}}>d^{27}$ and corollary 2 holds, then the higher the size of a group vis-a-vis the others $w_{1}>w_{2}>\ldots>w_{n}$, the lower the attitude in group-specific tax evasion $\alpha_{1}<\alpha_{2}<\ldots<\alpha_{n}$, ceteris paribus. Therefore, the biggest group bears the highest tax burden, and the smaller ones proportionally less.

Proof From corollary 2

$$
\begin{gathered}
\frac{\partial x_{i}^{*}}{\partial \gamma_{i}}=\frac{\left[2 \epsilon\left(1+k+t_{i}+\epsilon\right)+k+t_{i}+1 / 2-\gamma_{i}\left(2+\gamma_{i}+4 \epsilon\right)\right]}{\left(\gamma_{i}+2 \epsilon+1\right)^{2}}<0 \\
\frac{\partial \theta^{*}}{\partial \gamma}=\frac{1 / 2+k+t-\epsilon[4(\epsilon+\gamma)+1]-\gamma(\gamma+2)}{(\gamma+2 \epsilon+1)^{2}}<0 ; \\
\frac{\partial x_{i}^{*}}{\partial t_{i}}=-\frac{2 \epsilon+1}{\left(\gamma_{i}+2 \epsilon+1\right)}<0, \frac{\partial \theta^{*}}{\partial t}=-\frac{1}{\gamma+2 \epsilon+1}<0 ; \\
w_{1}>w_{2}>\ldots>w_{n} \Longrightarrow \gamma_{1}>\gamma_{2}>\ldots>\gamma_{n} ; t_{1}>t_{2}>\ldots>t_{n} \Longrightarrow \\
x_{1}^{*}<x_{2}^{*}<\ldots<x_{n}^{*} \Longrightarrow \alpha_{1}^{*}>\alpha_{2}^{*}>\ldots>\alpha_{n}^{*}
\end{gathered}
$$

Table 6

$n$ Citizen Groups

\begin{tabular}{l|l|l|l|l|l}
\hline Group $i$ & \multirow{2}{*}{$\begin{array}{l}\text { Parameters' Space } \\
\text { Tax regime }\end{array}$} & Weight & $\begin{array}{l}\text { Tax } \\
\text { Revenue }\end{array}$ & $\begin{array}{l}\text { Tax evasion } \\
\text { Cost }\end{array}$ & $\begin{array}{l}\text { Tax evasion } \\
\text { Attitude }\end{array}$ \\
& & & & \\
\hline Type-1 & ONLY third-party reporting & $w_{1}\left(>w_{2}\right)$ & $\gamma_{1}\left(>\gamma_{2}\right)$ & $t_{1}\left(>t_{2}\right)$ & $\alpha_{1}^{*}\left(<\alpha_{2}^{*}\right)$ \\
Type-2 & $\ldots$ & $w_{2}\left(>w_{3}\right)$ & $\gamma_{2}\left(>\gamma_{3}\right)$ & $t_{2}\left(>t_{3}\right)$ & $\alpha_{2}^{*}\left(<\alpha_{3}^{*}\right)$ \\
Type-3 & $\ldots$ & $w_{3}\left(>w_{4}\right)$ & $\gamma_{3}\left(>\gamma_{4}\right)$ & $t_{3}\left(>t_{4}\right)$ & $\alpha_{3}^{*}\left(<\alpha_{4}^{*}\right)$ \\
Type-4 & $\ldots$ & $w_{4}\left(>w_{5}\right)$ & $\gamma_{4}\left(>\gamma_{5}\right)$ & $t_{4}\left(>t_{5}\right)$ & $\alpha_{4}^{*}\left(<\alpha_{5}^{*}\right)$ \\
$\ldots$ & $\ldots$ & $\ldots$ & $\ldots$ & $\ldots$ & $\ldots$ \\
Type-n & ONLY self-reported income & $w_{n}(\min )$ & $\gamma_{n}(\min )$ & $t_{n}(\min )$ & $\alpha_{n}^{*}(\max )$ \\
\hline
\end{tabular}

\section{Imperfect information: Simultaneous Game}

Suppose now that the game is played simultaneously, as in Figure 11 .

\footnotetext{
${ }^{27}$ The extension to $n$ groups holds when the $\frac{\partial t_{i}}{\partial w_{i}}>0$ for all $i$. The case in which there is no direct ranking of sizes and costs will entail a more complicated solution computation, due to the contrasting effect of $t_{i}$ and $\gamma_{i}$, but it would be always possible to find a distribution in equilibrium.
} 
Figure 10

Weights and Tax Evasion in Equilibrium

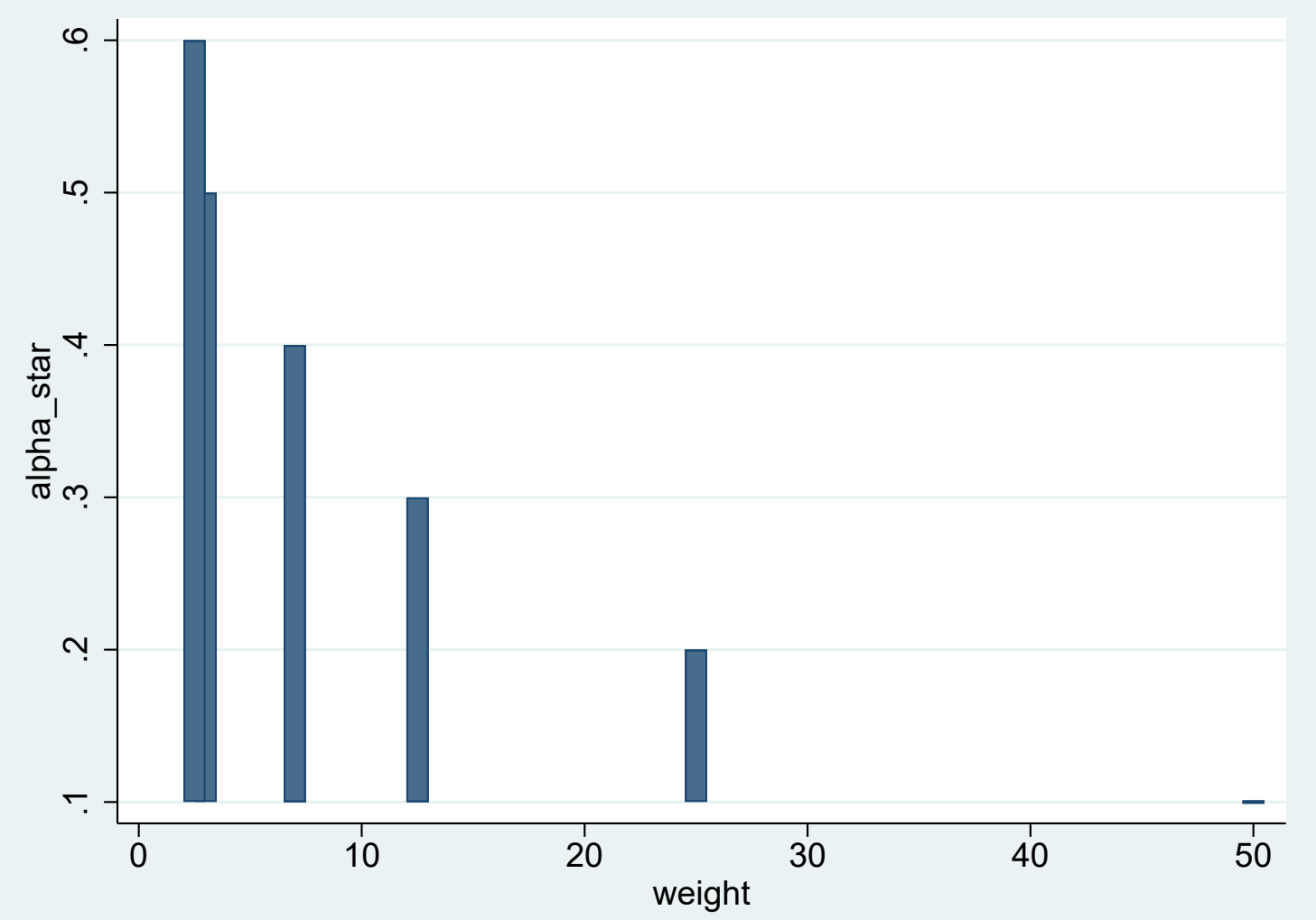

Figure 11

Timing: Simultaneous Play and Uncertainty

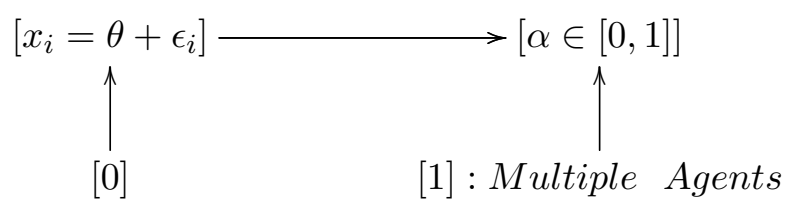

[Enforce vs not - Enforce]

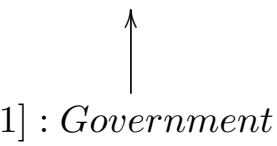


Proposition 4 In a simultaneous game in which a continuum of agents faces uncertainty about the economy institutional quality and coordination failure amongst themselves (simultaneous game with imperfect information) there is one Bayes-Nash Equilibrium determined by:

$$
\begin{gathered}
x^{*}=\theta^{*}+\frac{\epsilon[3 \gamma-2(k+t)]}{\gamma+2 t+1} \\
\theta^{*}=\frac{\epsilon[1+2(k-\gamma)]+\gamma(1+k-\gamma)-t+\frac{1}{2}}{\gamma+2 \epsilon+1}
\end{gathered}
$$

Taxes are enforced if the value of $\theta$ selected by nature is greater than $\theta^{*}$. Otherwise there is no tax enforcement.

Proof See proof of Proposition (3) and the following proof.

The sequential model can be solved by backward induction. In that case we looked at government's action, whose disadvantage relies in moving only in period 2, that is, in reaction to the agents' actions. However, the government has the 'advantage' of playing without uncertainty, i.e. $\theta$ is perfectly known. The government will enforce only if $\theta$ falls below a threshold that is computed in the proof of Proposition (3), namely equation (10). In turn, agents evade only if their signal falls below a threshold $x^{*}$, equation (9), the reason being that they know that the government has perfect information and that it will play according to the observed $\alpha$ and the $\theta$ known by the government (but not by them).

Given $E(\alpha)=S\left(\theta, I_{x^{*}}\left(x_{i}\right)\right)$

$$
S\left(\theta, I_{x^{*}}\left(x_{i}\right)\right)=\left\{\begin{array}{lll}
1 & \text { if } x^{*}>\theta+\epsilon & \theta<x^{*}-\epsilon \\
\frac{1}{2}-\frac{1}{2 \epsilon}\left(\theta-x^{*}\right) & \text { if } x^{*} \in[\theta-\epsilon, \theta+\epsilon] & \theta \in\left[x^{*}-\epsilon, x^{*}+\epsilon\right] \\
0 & \text { if } x^{*}<\theta-\epsilon & \theta>x^{*}+\epsilon
\end{array}\right.
$$

Is there any reason for which the observed $\alpha$ (sequential game) could be different from the expected $\alpha$ (simultaneous game)? The government's information set is unchanged and the optimal strategy is independent from playing simultaneously or sequentially; also, agents know that the state will not change its strategy and they will not change their strategies either.

Propositions (3) (1) are indeed identical, and the simultaneous and sequential games have the very same equilibrium outcome.

Q.E.D.

\section{Acknowledgments}

I would like to thank Giovanni Dosi, Guido Tabellini, Matteo Cervellati, Jan Fidrmuc, Enriqueta Aragones, Carlo Fiorio and Luca Andriani and two anonymous referees for their very valuable comments. 


\section{References}

Allingham, G. M., And A. Sandmo [1972], "Income Tax Evasion: A Theoretical Framework", Journal of Public Economics, Vol. 1, Issue 3-4 , pp. 323-338.

Bennet, J., And S. Estrin [2013], "Regulatory Barriers and Entry into a New Competitive Industry", Review of Development Economics, 17(4), 685698.

Black, Kraakman and Tarassova [2000], "Russian Privatisation and Corporate Governance: What Went Wrong?", Stanford Law Review, 1731-1808.

Bork, Rainald [2004], "Stricter Enforcement may increase tax evasion", European Journal of Political Economy, Volume 20, Pages 725-737.

Boycko, Shleifer And Vishny (1995). Privatising Russia, Cambridge, Massachusetts, M.I.T. Press.

Campos, N. F. Giovannoni [2006], "The Determinants of Asset Stripping: Theory and Evidence from the Transition Economies", Journal of Law and Economics, Vol. 49, No. 2 (October), pp. 681-706.

Carlsson, H., and Eric van Damme [1993a], "Equilibrium Selection in Stug Hunt Games", in Frontiers in Game Theory, A.P. Kirman (eds.).

Carlsson, H., and Eric van Damme [1993b], "Global Games and Equilibrium Selection", Econometrica, Vol. 61, No. 5 (September).

Cooper, R. W. [1999], Coordination Games: Complementarities and Macroeconomics, Cambridge University.

Cooter, R. D. [1996], "The Rule of State Law and the Rule-of-Law State: Economic Analysis of the Legal Foundations of Development", Annual World Bank Conference on Development Economics 1996, http://works.bepress.com/robert_cooter/48.

Dixit, A. K. [2006], Lawlessness and Economics, Princeton University Press, Princeton and Woodstock.

Filippin, A., C. V. Fiorio And E. Viviano [2013], "The effect of tax enforcement on tax morale", European Journal of Political Economy, Volume 32, Pages 320-331.

Frey, Bruno and Benno Torgler [2007], "Tax morale and conditional cooperation", Journal of Comparative Economics, Volume 35, Pages 136-159.

Guriev, S. [2004], "Red Tape and Corruption", Journal of Development Economics, 73(2], June 2004, 489-504.

Hoff, K., And J. E. Stiglitz [2004a], "After the Big Bang? Obstacles to the Emergence of the Rule of Law in Post-Communist Societies", American Economic Review, 94(3], June 2004, 753-763. 
Hoff, K., And J. E. Stiglitz [2004b], "The Transition Process in Post-Communist Societies: Towards a Political Economy of Property Rights", in Bertil Tungodden, Nicholas Stern, and Ivar Kolstad, (Eds). Towards Pro-Poor policies Aid, Institutions and Globalisation. New York: Oxford University Press (for the World Bank], pp. 231-245.

Hoff, K., And J. E. Stiglitz [2008] "Exiting a Lawless State", Economic Journal, Vol. 118, pp. 1474-1497.

Kandori, M. [1992], "Social Norms and Community Enforcement", Review of Economic Studies, Vol. 59(1), pp. 63-80.

Katz, A. W . [2008], "Contractual Enforcement Institutions and the Structure of Information", Journal of Institutional and Theoretical Economics, Vol. 164(1), pp. 134-154 (March).

Kleven, Henrik Jacobsen, Martin B. Knudsen, Claus Thustrup Kreiner, Soren Pesersen and Emmanuel Saez [2011], "Unwilling or Unable to Cheat? Evidence from a Tax Audit Experiment in Denmark", Econometrica, Volume 79, N. 3, Pages 651-692.

Lago-Penas, I. and S. Lago-Penas [2010], "The determinants of tax morale in comparative perspective: Evidence from European Countries", European Journal of Political Economy, Volume 26, Pages 441-453.

Levin, Mark and Georgy Satarov [2000], "Corruption and institutions in Russia", European Journal of Political Economy, Volume 16, Pages 113-132.

Licht, A. N., C. Goldschmidt and S. H. Schwartz [2007], "Culture Rules: The Foundations of the Rule of Law and Other Norms of Governance", Journal of Comparative Economics, Vol. 35 (4], pp. 659-88.

Luttmer, Erzo F. P. And Monica Singhal [2014], "Tax Morale", Journal of Economic Perspectives, Vol. 28, pp. 149-168.

Morris, S., And H. S. Shin [1998], "Unique Equilibrium in a Model of Self-Fulfilling Currency Attacks", American Economic Review, Vol. 88, No. 3 (June).

Murphy, Kevin M., A. Schleifer and R. W. Vishny [1989], "Industrialisation and the Big Push", Journal of Political Economy, Vol. 97 (5], pp. 1003-1026.

Murphy, Kevin M, A. Shleifer and R. W. Vishny [1993], Why "Is Rent-Seeking So Costly to Growth?", American Economic Review, Vol. 83(2], pages 409-14, May.

Myles, Gareth D. [2000], "Wasteful government, tax evasion, and the provision of public good", European Journal of Political Economy, Vol. 16, Pages 51-74. 
Myles, Gareth D. And Robin A. Naylor [1996], "A model of tax evasion with group conformity and social customs", European Journal of Political Economy, Vol. 12, Pages 46-66.

NAYlor, Robin A. [1990], "A social custom model of collective action", European Journal of Political Economy, Vol. 6, Pages 201-2016.

North, D. C., And Barry R. Weingast [1989], "Constitutions and Commitment: The Evolution of Institutional Governing Public Choice in Seventeenth-Century England", The Journal of Economic History, vol. 49, No. 4. pp. 803-832.

Obstfeld, M. [1996], "Models of Currency Crises with Self-Fulfilling Features", European Economic Review, Vol 40 (3-5], pp. 1037-47.

Orviska, Marta And John Hudson [2002], "Tax evasion, civic duty and the law abiding citizen", European Journal of Political Economy, Volume 19 , Pages 83-102.

Roland, G. [2001], "Ten Years After...Transition and Economics", IMF Staff papers, Vol. 48, Special Issue.

Roland, G. [2004], "Understanding institutional change: Fast-Moving and SlowMoving Institutions", Studies in Comparative International Development, 2004.

Roland, G., And T. Verdier [2003], "Law Enforcement and Transition", European Economic Review, Volume 47, Issue 4, Pages 669-685 (August 2003).

Schneider, Friedrich [2005], "Shadow Economies around the World: What Do We Really Know?", European Journal of Political Economy, Volume 21, Issue (3), pages 598-642.

SCHNEIDER, Friedrich [2017], "Shadow Economies around the World: New Results for 158 Countries over 1991-2015", Working Paper No. 1710, Department of Economics, Johannes Kepler University of Linz.

SchneIder, Friedrich And Dominik Enste [2000], "Shadow Economies: Size, Causes, and Consequences", Journal of Economic Literature, Volume 38, pages 77114 .

Slemrod, Joel [2007], "Cheating Ourselves: The Economics of Tax Evasion", Journal of Economic Perspectives, Volume 21, Issue (1), Pages 25-48.

Sonin, K. [2003], "Why the Rich May Favor Poor Protection of Property Rights", The Journal of Comparative Economics, vol. 31 pp. 715-731.

Torgler, Benno [2005], "Tax morale and direct democracy", European Journal of Political Economy, Volume 21, Pages 525-531.

TrAXler, C. [2010], "Social norms and conditional cooperative taxpayers", European Journal of Political Economy, vol. 26, Pages 89-103. 
Weingast, B. R. [1997], "The Political Foundations of Democracy and The Rule of Law", The American Political Science Review, vol. 91, No. 2. pp. 245-263.

Williamson, O. [2000], "The New Institutional Economics: Taking Stock, Looking Ahead", Journal of Economic Literature, vol. 38, No. 3. pp. 595-613.

Randolph Luca Bruno

University College London

School of Slavonic and East European Studies

16, Taviton Street

London

WC1H OBW

E-mail:

randolph.bruno@ucl.ac.uk 